\title{
Effects of land use changes on climate in the Greater Horn of Africa
}

\author{
Vincent O. Otieno*, R. O. Anyah \\ Dept. of Natural Resources and the Environment, University of Connecticut Storrs, Connecticut 06269, USA
}

\begin{abstract}
The relationships between historical land use transformations and spatio-temporal patterns of precipitation and temperature over the Greater Horn of Africa (GHA) were examined based on Landsat satellite observations for the years 1986, 1995, and 2000 and regional climate model simulations in the period 1991-2000. The satellite-derived land use/cover classification shows increased conversion of large portions of forests over the GHA to agriculture, particularly in Kenya, with land (acreage) under crops increasing from $6.55 \%$ in 1986 to almost $18 \%$ by the year 2000. Sensitivity experiments performed with regional climate model, Version 4 (RegCM4), indicate that expanding agriculture into forested areas led to a modest reduction in monthly rainfall totals and also may be contributing to notable shifts in moisture convergence zones and centers of rainfall maxima. Student's $t$-test at a 0.1 significant level showed a decrease in precipitation and an increase in surface temperature around the lake region when surface vegetation cover is converted to agricultural land cover type. Conversely, under the assumption that large sections of croplands are converted to forest, the simulations resulted in a modest increase in precipitation and a reduction of surface temperature around the lake region, changes that are significant at the 0.1 confidence level. A substantial trade-off in the components of the surface energy balance between sensible heat flux (SHF) and latent heat flux (LHF) was observed for the different conversion types. Under the assumption of reforestation, both SHF and LHF increased. The increase in SHF was almost twice that of LHF. On the other hand, when land cover types were converted to agricultural types, SHF decreased, while LHF did not show any significant change.
\end{abstract}

KEY WORDS: Regional climate modeling $\cdot$ Land use/land cover change $\cdot$ Land cover classification · Climate variability

Resale or republication not permitted without written consent of the publisher

\section{INTRODUCTION}

Land surface characteristics, e.g. surface roughness, albedo, and moisture availability, strongly control land-atmosphere interactions. Through turbulence, these surface conditions play a major role in the transfer of mass, momentum, and heat in the planetary boundary layer (PBL). The PBL provides a vital physical link between the atmosphere and the surface of the earth for the exchanges of heat, moisture, and momentum fluxes. Hence, the primary source of energy for driving the atmospheric circulations is at the surface of the earth (Seth \& Giorgi 1996). Therefore, realistic estimate of these fluxes is central to the satisfactory performance of numerical weather and climate models (Zheng \& Eltahir 1997, Chase et al. 1999, Gibbard et al. 2005, Ge et al. 2008). Over the past decades, land use and land cover (henceforth land use/cover) has been widely recognized as a critical factor mediating socioeconomic, political and cultural behavior and global climate change (IPCC 2001). Land use/cover forms the lower boundary of the atmosphere and is thus a major component of climate variability. Human modification of the land surface therefore affects regional to global climate processes by changing the fluxes of mass and energy between an ecosystem and the atmosphere (Pielke et al. 2002). 
Several attempts have been made to understand past climate changes and to project potential future climate changes by incorporating reconstructed historical land cover changes and projected possible future land cover changes into numerical simulations (e.g Xue 1997, Chase et al. 2000, DeFries et al. 2002). Recent studies such as that of Feddema et al. (2005) suggest that land use/cover change is a first-order climate effect at the global scale. Therefore, interactions between the biosphere and atmosphere have been the focus of numerous climate-modeling studies (e.g. Taylor et al. 2002). Recently, Ge et al. (2007) incorporated moderate resolution imaging spectroradiometer data of the leaf area index and vegetation fractional cover in the regional atmospheric modeling system (RAMS). The objective was to examine how the classification accuracy of a land cover data set employed in a land surface scheme affects simulated cumulated precipitation in a regional climate model. Their results showed that spatial, seasonal, and diurnal characteristics of the RAMS-simulated land surface temperature (LST) over East Africa were improved. Specifically, the inter-tropical convergence zone-related migration, bimodal temporal variation, and monthly averaged diurnal cycles of LST were more realistically reproduced. This highlighted the need to realistically represent the spatial and temporal distribution of vegetation, which can significantly improve land-atmosphere modeling.

Over the Greater Horn of Africa (GHA), and particularly in Kenya, some efforts have been made to reconstruct historical land cover changes (Serneels et al. 2001, Baldyga et al. 2007, Clark \& Pellikka 2007). Just a few of these efforts and studies (e.g. Mutie et al. 2005, Notter et al. 2007, Githui et al. 2008, 2009) have made attempts to link land use/cover change over parts of Kenya to stream flow changes. However, it is not yet clear how land use/cover change affects hydroclimatic variability over the region. Nonetheless, the significance of vegetation changes on the hydrological cycle (Seth \& Giorgi 1996, Zheng \& Eltahir 1997, Chase et al. 1999, Li \& Xue 2005, Ge et al. 2008) has been established elsewhere. Characterizing land use/cover change and further assessment of hydroclimatic effects is a fundamental step in providing a baseline for understanding the land cover relationship to hydroclimatic variability within the region, especially within water catchment and surrounding areas. This will be important for future climate change impact assessments and for the management of scarce water resources.

Hence, in the present study we examine the potential impacts of land use/cover transformations on regional/local climate over Kenya, using both satellite-derived land use classification and conducting sensitivity simulations using the RegCM4 model described in detail in Giorgi et al. (2012, this Special).

\section{DATA AND NUMERICAL SIMULATIONS}

The present study consists of 2 major parts. The first part involved the analysis of satellite data using ERDAS IMAGINE, a raster graphic editor and remote sensing application tool that allows the user to prepare, display, and enhance digital images for mapping use (Leica Geosystems 2002), to classify land cover over our study region-the central Greater Horn of Africa (Kenya). The second part involved conducting a suite of sensitivity experiments using the RegCM4 model. In numerical experiments we specifically tested the response of the climate parameters (temperature and precipitation) over the western and central parts of Kenya to perturbations in land cover. Different prescriptions (conversions) of agricultural and forested areas in the model were also used in the sensitivity experiments to give the best representation possible of the land use/cover transformations derived from Landsat data for the periods 1986, 1995, and 2000. Detailed descriptions of both the Landsat-based land use classification and the numerical experiment design are described in the following sub-sections.

\subsection{Land cover/use classification using remote sensing technique}

Landsat scenes obtained from the United States Geological Survey (USGS) Earth Resource Observation and Science Center (EROS) were used in the present study. A total of 33 Landsat scenes were obtained from the USGS (available at http://glovis.usgs.gov/). Only Landsat thematic mapper (TM) data for which the classifications 'best quality' and 'cloud free 0 ' (0 to $10 \%$ ) were chosen. These images represented about the only usable satellite data for the study area because of the presence of heavy cloud cover for most of the periods under study. The years 1986, 1995, and 2000 were chosen based on data availability and since they also corresponded to pre-vegetation degeneration and vegetation degeneration periods (pre- and post1995, respectively). The images were inspected for systematic radiometric and geometric distortions and found to be free of defects. This was expected since only data of the highest quality were chosen, and non- 
system-related distortions had been corrected prior to the release of the data (Arino et al. 1998). This was important for better radiometric contrast and mosaicking of images taken at different times.

A remote sensing tool, ERDAS IMAGINE 9.3, was used to perform unsupervised classification of the Landsat images. The classification of an image for identification of terrestrial features was based on spectral analysis. Initially, the iterative self-organizing data analysis technique (ISODATA; Memarsadeghi et al. 2003, 2007) in ERDAS IMAGINE 9.3 (Leica Geosystems 2002) was used to perform an unsupervised classification on Landsat images resulting in a chosen number of clusters. Pixels that could be clearly identified as belonging to a particular informal class of vegetation were extracted, thereby reducing spectral variability across the remaining pixels. We first performed a generalized unsupervised classification with 7 categories that included water body, agricultural fields, savannah/shrub/grassland, dense vegetation/forest, barren/salt marsh, built up areas, and a class of unknown categories. In this case the spectral pattern present within the data for each pixel was used as the numerical basis/strength for categorization. An ISODATA of 75 classes was generated for classification. A similar number of classes were then generated to identify the 'unknown class' within the 6 categories. The 2 images were subsequently merged to create a fully classified image.

\subsection{Model sensitivity experiment}

The model used in this experiment is the International Center for Theoretical Physics' (ICTP) regional climate model, Version 4 (RegCM4) (Pal et al. 2007, Elguindi et al. 2011, Giorgi et al. 2012). RegCM4 is a 3-dimensional primitive equation atmospheric model based on the NCAR/Penn state mesoscale model, Version 5 (MM5; Grell et al. 1994). Thus, it is a compressible primitive equation model currently based on hydrostatic dynamics only. The model uses a terrain-following (sigma-pressure) vertical coordinate system. Large-scale precipitation parameterization is based on the subgrid explicit moisture scheme (SUBEX; Sundqvist et al. 1989, Pal et al. 2000), while parameterization of cumulus convection is based on the Grell convective scheme (Grell 1993), with the Fritsch \& Chappell closure assumption. The radiative transfer scheme is derived from the NCAR CCM3 (Kiehl et al. 1996) package, and the land scheme is based on the biosphere-atmosphere transfer scheme (BATS 1e; Dickinson et al. 1993). The boundary layer physics is based on the nonlocal scheme of Holtslag et al. (1990). A detailed description of the RegCM4 model is available in Giorgi et al. 2012 and Elguindi et al. (2011).

Previous studies (e.g Giorgi et al. 1996, Seth \& Giorgi 1998, Xue et al. 2007) have established the impact of domain size on the simulation of RCMs. Our domain choice, after some preliminary simulations, was mainly centered in Kenya, extending east into the Indian Ocean and southern Somali, west into Uganda and the Congo (covering most of the Congo forest), north encompassing southern parts of the Sudan and Ethiopia (including the Ethiopian highlands and horn of Somali), and south into Tanzania (Fig. 1). The simulation was performed on the domain centered at $1.5^{\circ} \mathrm{S}$ and $38^{\circ} \mathrm{E}$. This domain is within the primary agricultural zone of the region. It

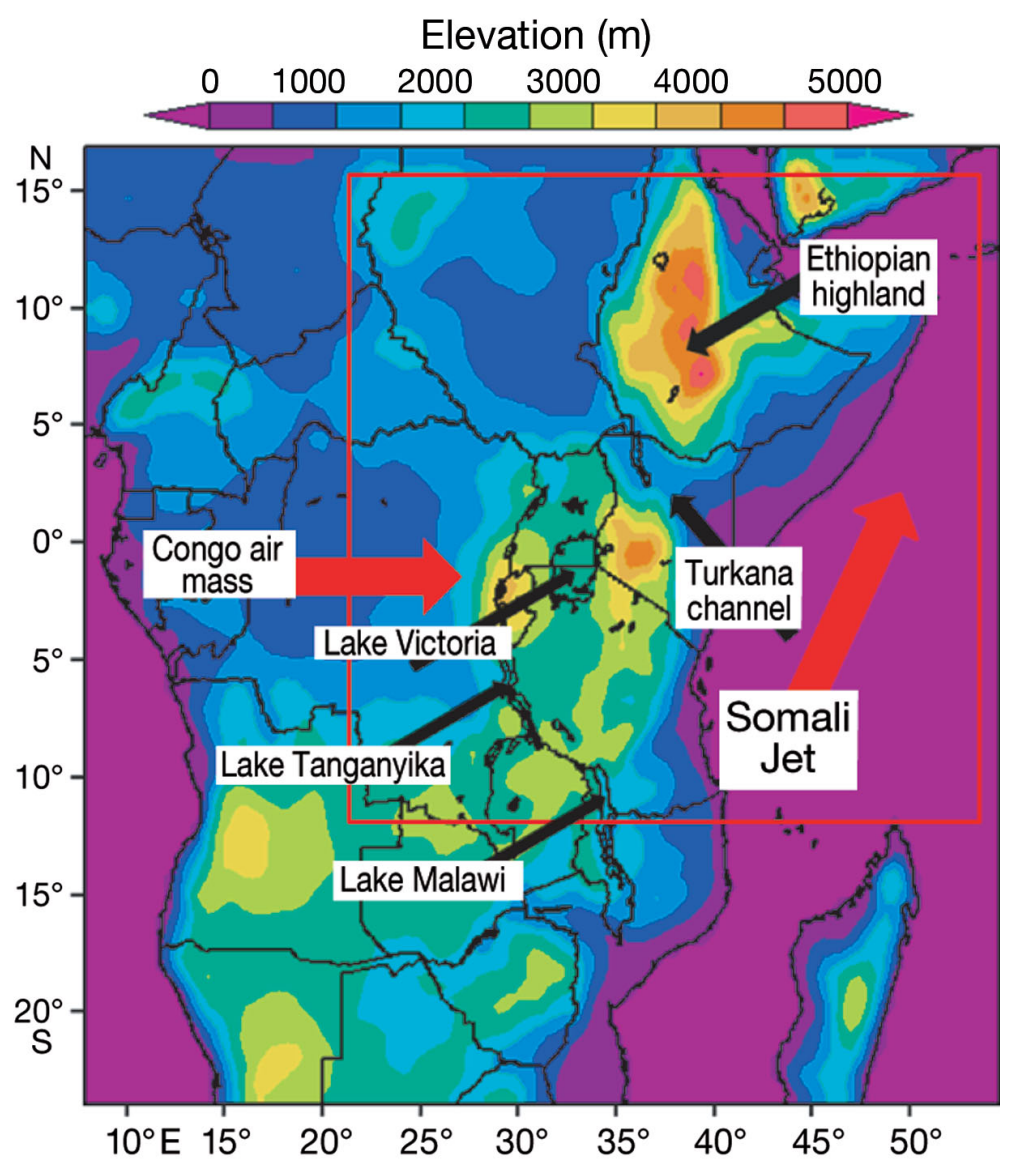

Fig. 1. Surface elevation of sub-Saharan Africa. Red box: Greater Horn of Africa countries 
is comprised of low lying and highland areas, including Lake Victoria, the Nandi hills, Cherangani, Kakamega, the Abaredare, and the Mau catchment. The domain contained 96 grid points in a longitudinal direction and 80 grid points in a latitudinal direction. The spatial horizontal resolution used in our simulations was $30 \mathrm{~km}$ with normal Mercator projection.

The initial and lateral boundary conditions were taken from ERA-Interim (Simmons et al. 2007, Uppala et al. 2008). ERA-Interim, which is produced by ECMWF, uses 4D-variational analysis on a spectral grid with triangular truncation of 255 waves (corresponds to approximately $80 \mathrm{~km}$ ) and a hybrid vertical coordinate system with 60 levels. The ECMWF global model is used for the forward integration in the 4D-variational analysis, and the temporal length of the variational window is $12 \mathrm{~h}$. This reanalysis covers the period from 1989 to present day. We utilized the $1.5^{\circ} \times 1.5^{\circ}$ latitude and longitude datasets. The National Center for Environmental Prediction (NCEP) - National Center for Atmospheric Research (NCAR) reanalysis data (Kalnay et al. 1996) were used for evaluating and analyzing surface flux variations over the region. Camberlin et al. (2001) validated several NCEP reanalysis variables (e.g. zonal and meridional components of the wind, geopotential height, air temperature, and specific humidity) using a split moving-window dissimilarity analysis over Africa. Their analysis found virtually no jumps in the above-mentioned variables over the GHA since 1979. The data therefore provided a general guidance against which model fluxes can be evaluated. The NCEP/NCAR data sets are reported every $6 \mathrm{~h}$, on 17 pressure levels from 1000 to $10 \mathrm{hPa}$ for various meteorological parameters. The data set covers the years 1948-present and is interpolated on a $2.5^{\circ} \times$ $2.5^{\circ}$ grid resolution.

To account for uncertainties in observed precipitation, we have used both the University of East Anglia's Climatic Research Unit (CRU) and The Global Precipitation Climatology Project (GPCP) data sets for evaluation of our RegCM4 simulated rainfall. CRU is available from 1901 to 2000. CRU data are derived from gauge observations over land areas only and are interpolated on a regular grid of $0.5^{\circ} \times 0.5^{\circ}$ (Mitchel et al. 2004). These data provide a long-term precipitation record and are available only on a monthly time scale. GPCP data sets (Adler et al. 2003), available on $2.5^{\circ} \times 2.5^{\circ}$ latitude-longitude global grids, incorporate precipitation estimates from low-orbit-satellite microwave data, geosynchronousorbit-satellite infrared data, and rain gauge observations. They also contain individual input fields, a combination of the microwave and infrared satellite estimates, and error estimates for each field. The data are available from 1979 to present. GPCP data sets are available for both land and ocean areas. This is useful in validating the model output over the oceans.

The sensitivity experiments are divided into sets that comprise mechanistic modification of surface cover in the agriculture and forest zones (Fig. 1) to either agricultural (see Fig. 9b) or forest (see Fig. 9c) categories. The first set of experiments involves a continuous 10 yr run that starts in July 1990 and ends in June 2001. The first 6 mo of each run is discarded for model spin up. The first run employed the default vegetation characteristics as distributed in the RegCM4 LANDUSE (see Fig. 9a); we refer to this experiment as the control experiment. The next 2 sets of experiments were done for sensitivity tests. These involved the modification of land cover characteristics described in the RegCM4 LANDUSE over the agriculture and forest zones (Fig. 1). In our first sensitivity experiment we tried to mimic agricultural expansion over the years 1986-2000 in the model, borrowing from ERDAS classification of 2000. Our second case assumes that, with an extensive reforestation program, most, if not all, of the deforested zones can be reclaimed; hence, we tried to mimic, again borrowing from ERDAS classification of 1986, the original land cover before the deforestation.

\section{RESULTS AND DISCUSSION}

\subsection{Land cover classification over Kenya}

From the reconstructed land use/cover, savannah/grassland/shrubs vegetation occupies most of the northern parts, the upper eastern, and a few parts of the southwestern region (Fig. 2). Agricultural activities, forests, and water bodies are concentrated within the western and Rift Valley parts of the country. Fig. 3 shows significant increase in agricultural activities between 1995 and 2000. The combined decrease in forested/dense vegetation coverage $(\sim 9 \%)$ and water coverage $(\sim 2 \%)$ almost balances the increase in agricultural land $(\sim 11 \%)$. This is a reflection of the direct conversion of forested and riverine areas to agricultural production, consistent with the earlier findings of Maingi \& Marsh (2001). The decrease in savannah vegetation is also consistent with changes in savannah/grassland areas to barren grounds reflected by an increase in barren acreage. 


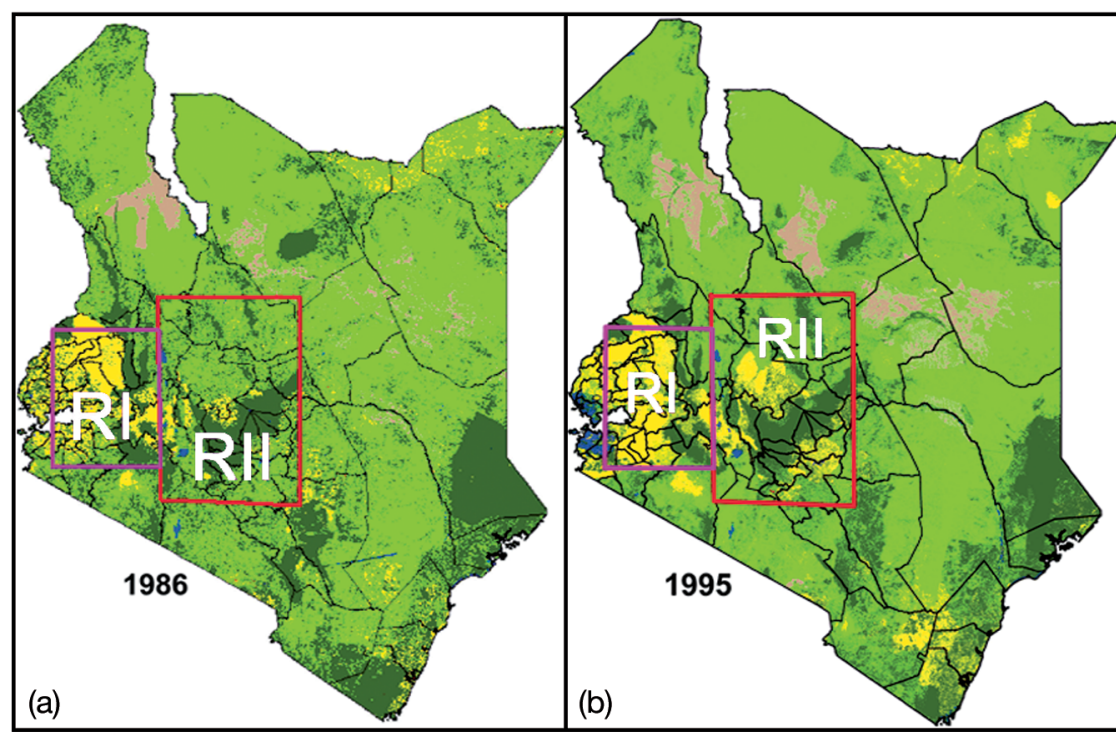

Fig. 2. Land use/cover transition in Kenya for the years (a) 1986, (b) 1995, and (c) 2000. Boxes: division of agricultural and forested areas into 2 regions (RI and RII, see Section 3.2)

(a)

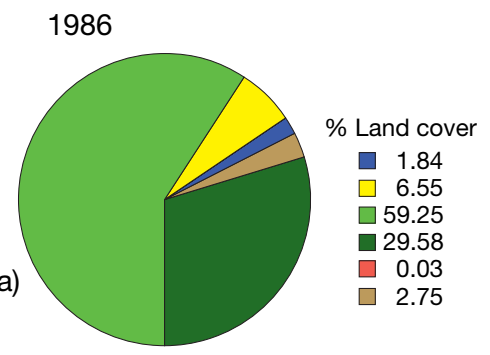

(b)
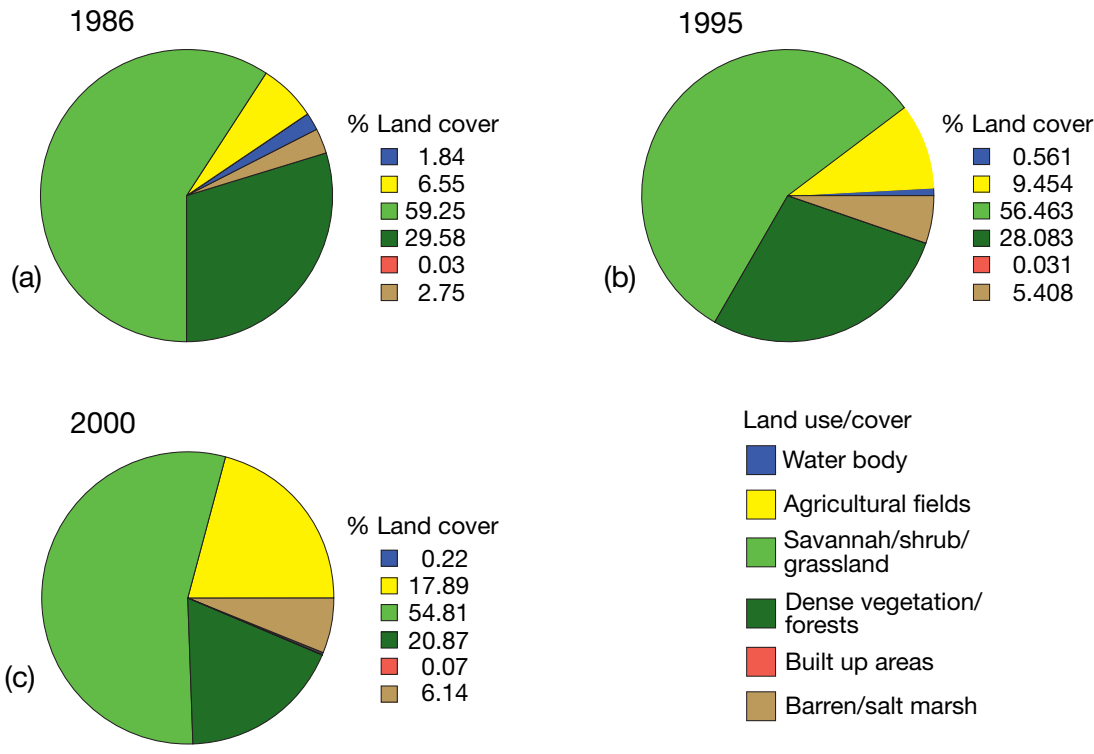

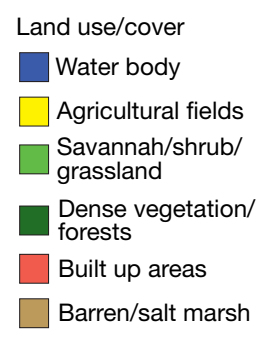

Fig. 3. Land use/cover statistics in Kenya for (a) 1986, (b) 1995, and (c) 2000

The significant transformation of land cover observed above could be a result of anthropogenic processes due to increased demand for more land. In the next section we look at some of the feedback of land use/cover transformations on local climate variability.
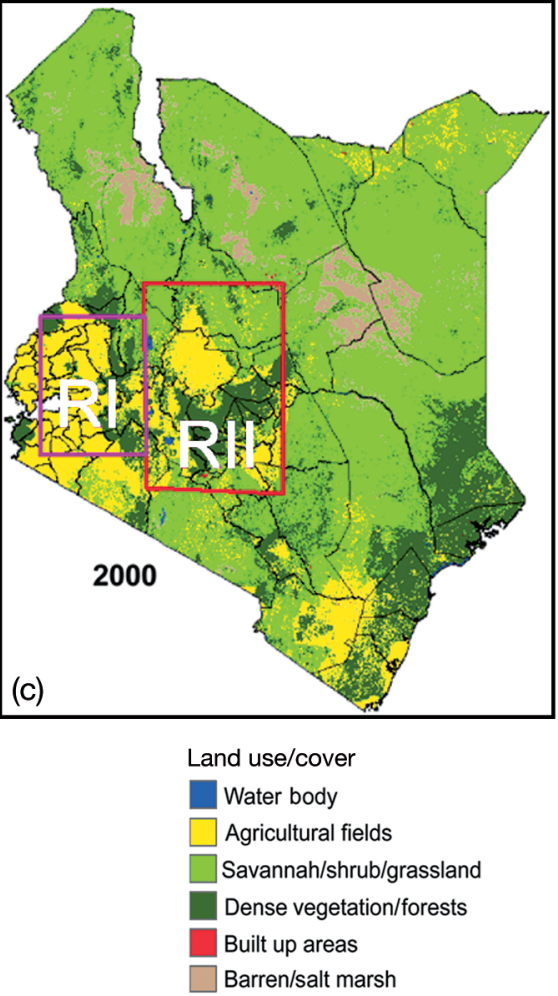

\subsection{Spatial variability of temperature and precipitation over Kenya}

Contour plots of CRU precipitation and temperature were used to present snapshots of the spatial climate variability over Kenya for different time periods (seasons). Seasonal (JF, MAM, JJA, and OND) precipitation and temperature (see Figs. 4 \& 5) can be compared with land use/cover (Fig. 2) for 1986, 1995, and 2000.

From the spatial plots for rainfall distribution in 1995, JanuaryFebruary (JF) seasonal precipitation was mainly concentrated in the western part of the country (Fig. 4a). During MAM, the primary rainfall season of the predominantly bimodal rainfall regimes in Kenya, precipitation was mainly concentrated in the lake region and the surrounding mountainous regions (e.g over Mau, Aberdare, and Mount Kenya), and also along the coastal region (Fig. 4b), with aver- 


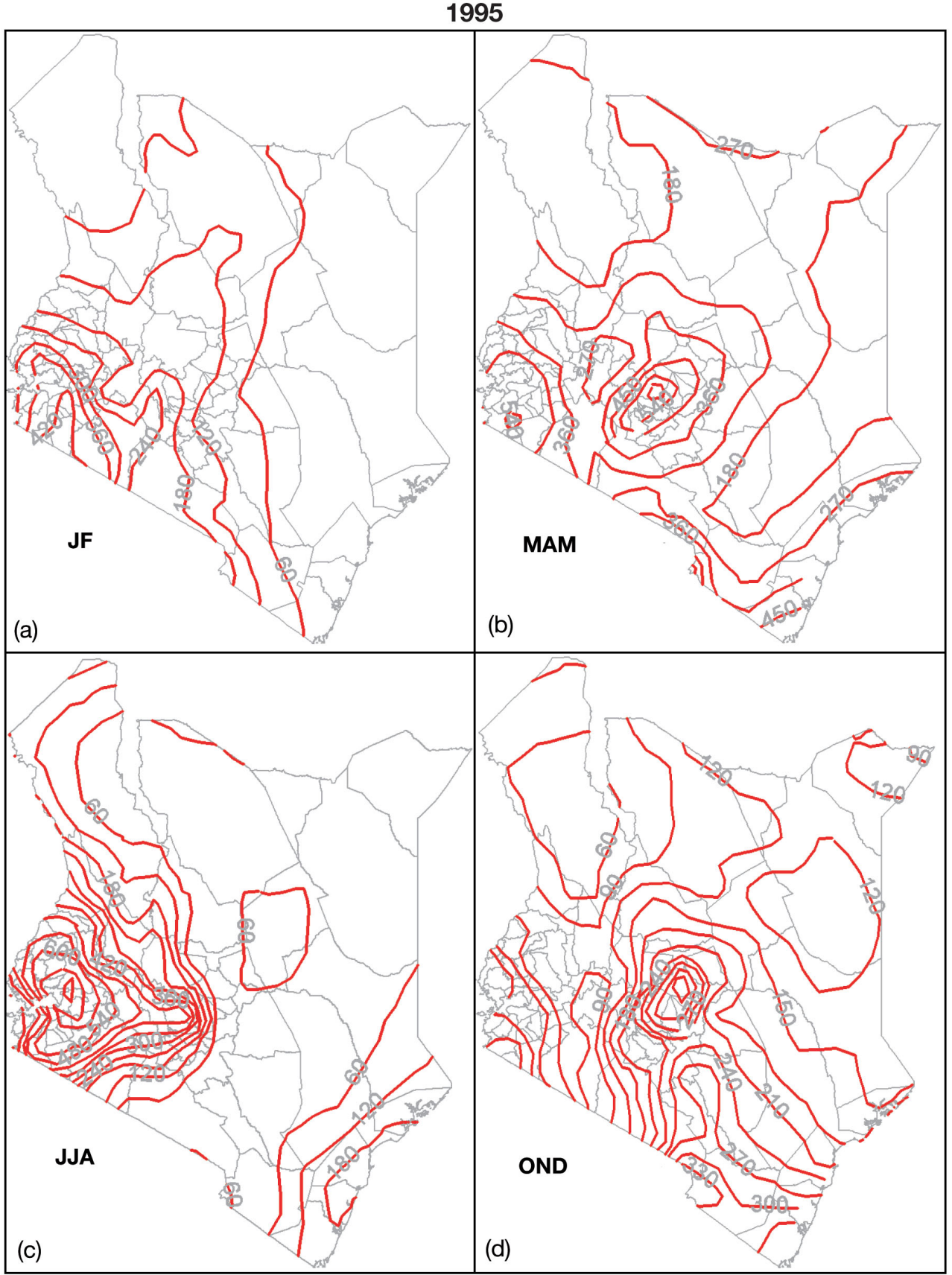

Fig. 4. Plots of average seasonal precipitation contours (mm) for 1995 in Kenya for (a) January-February (JF), (b) March-AprilMay (MAM), (c) June-July-August (JJA), and (d) October-November-December (OND)

age precipitation as high as $540 \mathrm{~mm}$ recorded over the Mount Kenya region. Similar to JF, the JJA seasonal rainfall was confined to the lake region and the western highlands of Kenya, extending to parts of the Rift Valley and central Kenya over the Mau catchment and Mount Kenya region (Fig. 4c). JF and JJA seasons are transition periods between the predominant bimodal (MAM and OND) rainfall regimes. These seasons are normally dry over the region. Similar to MAM, the OND rainfall distribution was also concentrated over the mountainous and coastal regions (Fig. 4d). Nonetheless higher amounts of rainfall are witnessed in many places during MAM than during OND.

Fig. 5 shows 1986 temperature anomalies for the 4 seasons of the year. During the JF season, temperature anomalies were positive over most parts of the country, with coastal and northeastern areas showing anomalies $>1{ }^{\circ} \mathrm{C}$ (Fig. 5a), while in most of the western parts of the country anomalies of $<1^{\circ} \mathrm{C}$ were 


\section{6}

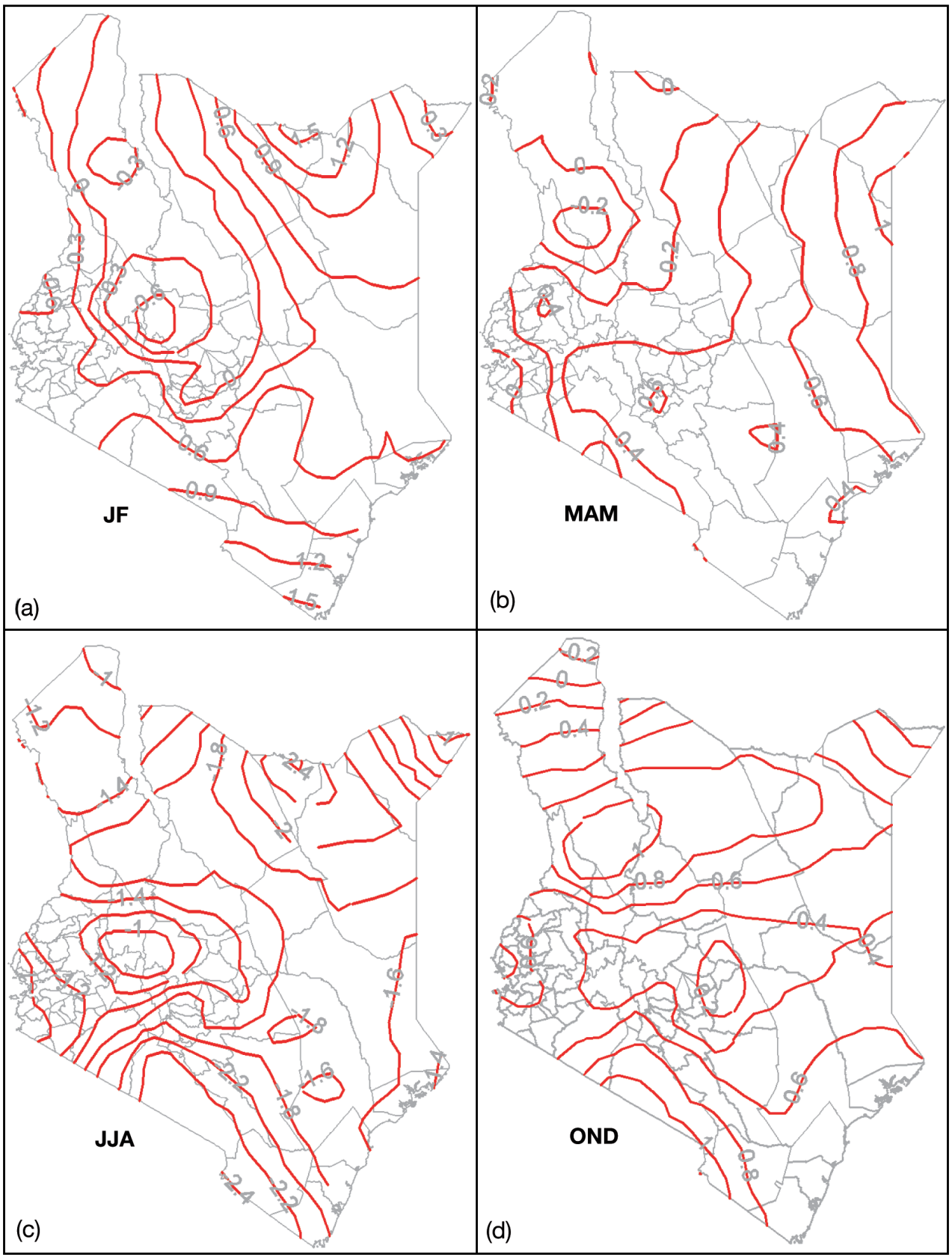

Fig. 5. Same as Fig. 4, but for 1986 temperature anomalies $\left({ }^{\circ} \mathrm{C}\right)$

recorded, including the largest decrease of $-0.6^{\circ} \mathrm{C}$ over the intersection of the Mau complex, Aberdare, and Mount Kenya (Fig. 5a). During the MAM season, observed temperature deviations from the long-term mean were higher on the eastern side of the country, decreasing towards the western side with the northwestern parts of the country around Turkana recording below normal temperatures in 1986 (Fig. 5b). Temperature anomalies $>$ or $<-1^{\circ} \mathrm{C}$ over most parts of Kenya were observed during JJA of 1986 (Fig. 5C), with higher negative temperature anomalies over the northeastern and coastal regions, decreasing gradually to $-1^{\circ} \mathrm{C}$ over forested areas on the western side of the country and in the lake region. Nonetheless, the temperature anomaly pattern depicted a zonal orientation, with lower negative temperature anomalies recorded around the lake region and higher negative temperature anomalies recorded over the eastern part of the country. In contrast to other seasons, an east-west temperature orientation depicted higher 
positive temperature anomalies on the western side of the country, decreasing towards the eastern side during the OND season (Fig. 5d). Nevertheless, higher positive temperature anomalies were recorded over the northwestern parts of the country, especially over the Turkana region. In general, observed temperatures depicted a zonal northeast-southwest temperature gradient, with higher temperatures observed mostly over the northeastern parts of the country and low temperatures observed mostly over the southwestern parts of the country around the mountainous/forested areas. This imitated the vegetation contrast over the country. The northeastern part of the country supports a mixture of savanna grassland, shrub, barren land, and salt marsh, while most of the southwestern part of the country has a mixture of forest, savannah grassland, and agricultural fields (Fig. 2a). Hence, lower surface temperatures over the southwestern parts of the country can be attributed to more latent heat flux (LHF; Li \& Xue 2005, Beltrán-Przekurat et al. 2011) than in the northeastern parts.

Based on both Landsat and USGS land use types (Fig. 2), agricultural activities are mainly concentrated over the western, central, and coastal parts of the country, which are collocated with centers of higher rainfall and lower temperature anomalies

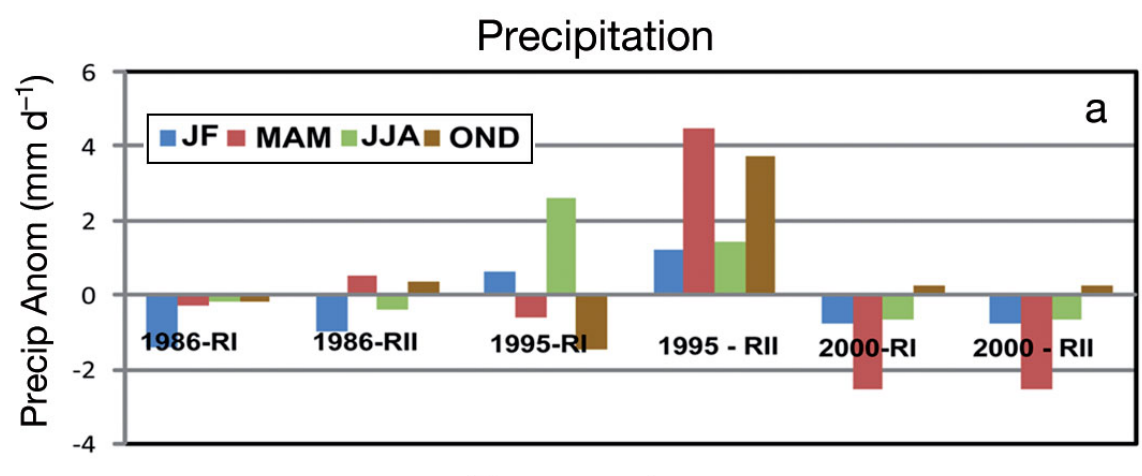

Temperature

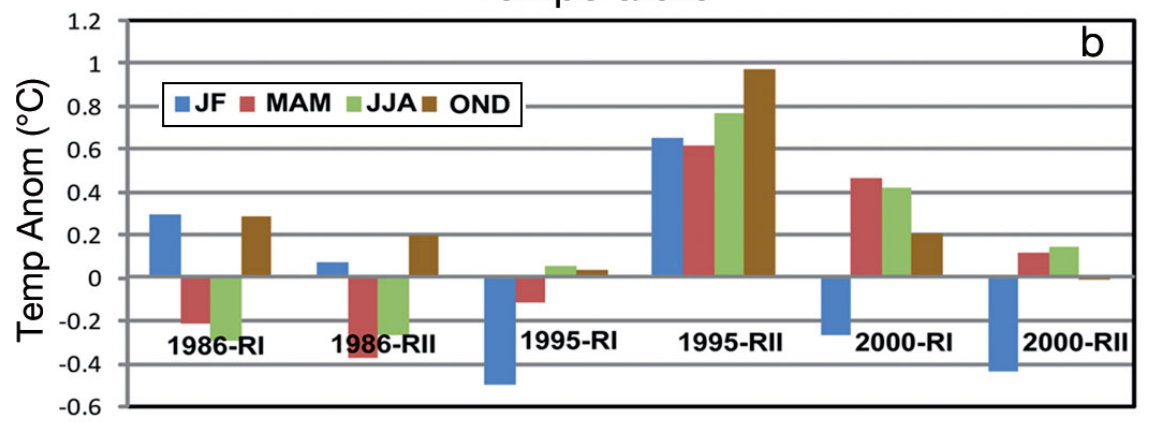

Fig. 6. Seasonal anomalies for Regions I and II (RI \& RII) in 1986, 1995, and 2000: (a) precipitation; (b) temperature. The long-term mean (LTM) is taken from 1971-2000 compared to the rest of the country. In addition, the main forests/dense vegetation areas are also located over the same regions. From Fig. 2 it is evident that agricultural activities increased in the 2 regions between 1986 and 2000. Similar changes (depicted in Figs. 2 \& 3) were noted earlier by Maingi \& Marsh (2001), who indicated that intensive agriculture over most of the region took place after 1995, leading to a tremendous reduction in forest cover.

Hence, to further examine precipitation and temperature differences over the 3 years and also investigate how land cover/use over the region contributes to the observed fluctuations, we focus our analysis on the western part of the country, which is the main agricultural basket of the region. We divided the agricultural/forest zone into 2 regions (Fig. 2). Region I (RI) extends from $1.4^{\circ} \mathrm{S}$ to $1.3^{\circ} \mathrm{N}$ and from $34^{\circ}$ to $36^{\circ} \mathrm{E}$. The topography of this region is very complex, as it has a number of hills and mountains comprising Mt. Elgon, the Kakamega (Kakamega forests), Nandi, and Cherangani hills, and the Mau complex. It also has a number of water bodies including Lake Victoria and Mara River among others. Region II (RII) extends from $2^{\circ} \mathrm{S}$ to $1.5^{\circ} \mathrm{N}$ and from $36^{\circ}$ to $38^{\circ} \mathrm{E}$. This region also has a complex topography, including the Aberdare forests and Mt. Kenya and also Lakes Naivasha and Nakuru.

Fig. 6a shows the observed seasonal rainfall total over the 2 regions for the years 1986, 1995, and 2000. Precipitation rates show 1995 recording above normal precipitation in JF and JJA in both RI and RII, as compared to 1986 and 2000 (Fig. 6a). The enhanced precipitation received during JF 1995 might have been a result of El Niño conditions that developed in 1994 extending into earlier months (January and February) of 1995, while the JJA precipitation might have been a result of the strong Somali jet resulting from La Niña conditions that were developing in 1995 and hence allowed advancement of westerlies from the Congo basin into the region (Harpen \& Woiceshyn 1999, 2001). This El Niño-Southern Oscillation (ENSO) condition might also have been enhanced by local convective factors (Mutai et al. 1998). However, for the 3 years, precipitation was low during the main rainfall seasons (MAM and OND). While OND seasonal rainfall has been linked to ENSO vari- 
(a) $\mathrm{RI}$ net radiation flux

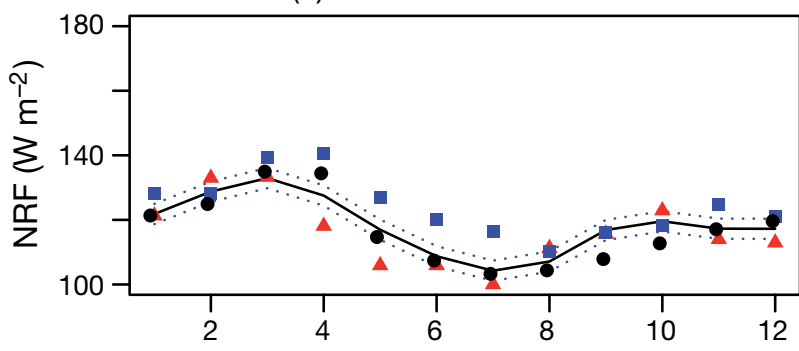

(c) RI sensible heat flux

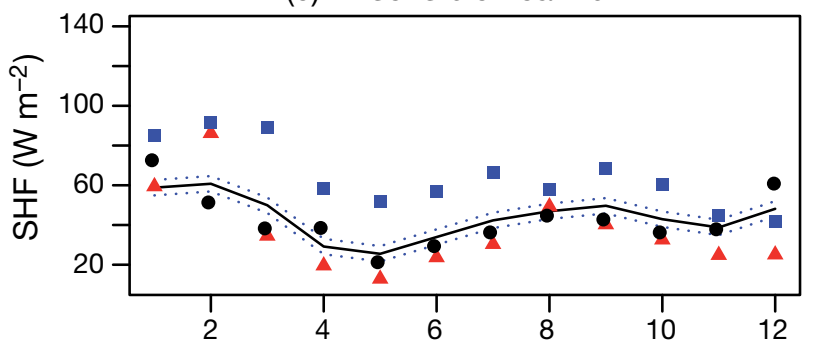

(e) RI latent heat flux

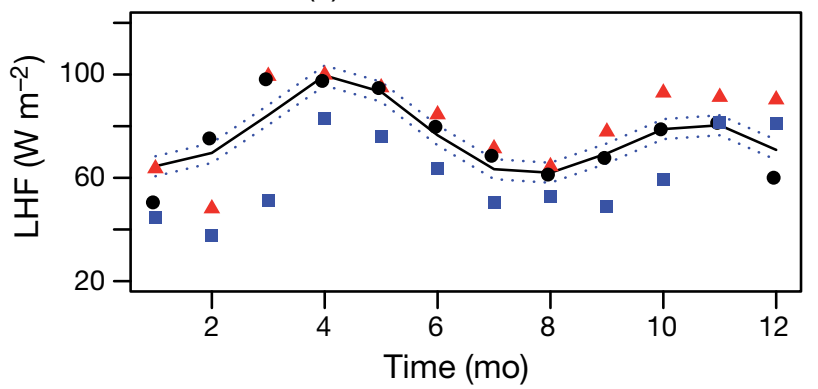

(b) RII net radiation flux

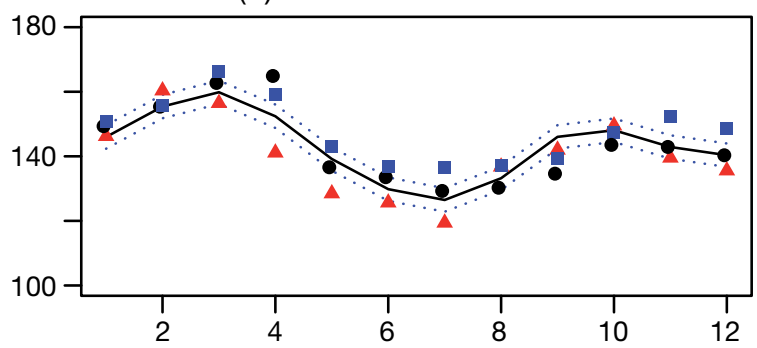

(d) Rll sensible heat flux

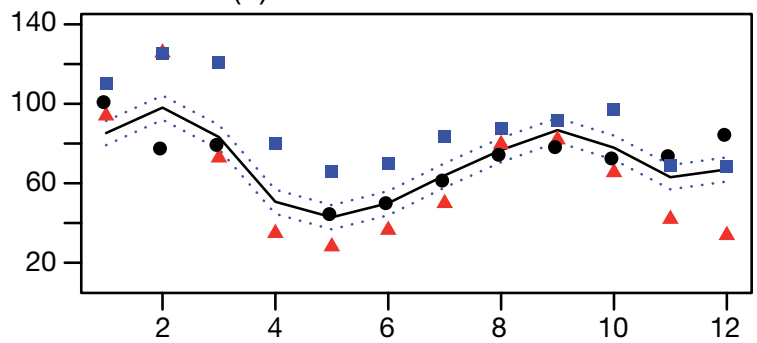

(f) RIl latent heat flux

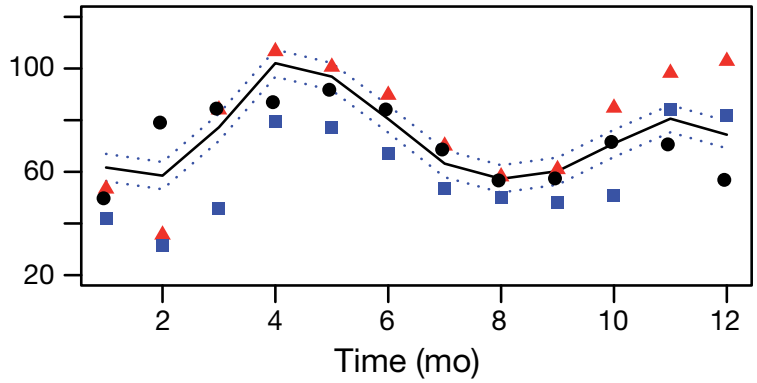

Fig. 7. National Center for Environmental Prediction reanalysis surface fluxes of $(a, b)$ net radiation (NRF), (c,d) sensible heat (SHF), and (e,f) latent heat (LHF) in Regions I and II for the years 1986 (red), 1995 (black) and 2000 (blue). Solid black line: monthly long-term mean (LTM, 1971-2000); dotted blue lines: $95 \%$ confidence intervals of the LTM

ability (e.g. Ogallo 1988, Hastenrath et al. 1993), uncertainty still remains concerning the relationship between MAM seasonal rainfall and ENSO events.

During 1986, below normal temperature anomalies were recorded from March to July over RI, while in the rest of the months temperatures above the longterm mean (LTM) were observed. Therefore, averaged seasonal temperatures were below the LTM during the MAM and JJA seasons (Fig. 6b). In RII, positive temperature anomalies were only observed during the months of February, October, and November; hence, slightly above normal average temperature anomalies were observed during the JF and OND seasons. Negative temperature anomalies were recorded in 1995 from January to June over RI, averaging below normal temperatures during $\mathrm{JF}$ and MAM seasons (Fig. 6b). However, in RII, temperature anomalies were above the LTM for all months of 1995, averaging above normal temperatures for all seasons. During 2000, negative temperature anom- alies were only witnessed in the earlier months of the year, averaging to below normal temperature during the JF season in both RI and RII (Fig. 6b).

Fig. 7 shows NCEP reanalysis surface fluxes for the years 1986, 1995, and 2000. From the plot, 2 peaks are observed in the surface fluxes that basically reflect the pattern of the bimodal rainfall regimes in the region. Higher LHF and precipitation rates are shown to occur between the periods of March-May and October-December. Similarly low sensible heat flux (SHF) is recorded between the periods of MarchMay and October-December. Typically sensible heat and latent heat co-vary negatively with each other, with an increase in latent heat often accompanied by a decrease in sensible heat and vice versa. Comparison of the surface flux changes in the 3 years (1986, 1995, and 2000) against the long-term mean shows significant increase (at the 0.25 confidence level) in net radiation flux (NRF) for the March to August period in 2000 (Fig. 7a) in RI. In RII, NRFs were within 
the confidence interval for most of the months. The changes in NRF were reflected in the changes in SHF and LHF, with significant increase and decrease in SHF and LHF, respectively, recorded in 2000.

From the observations (Fig. 6a), RI showed a continuation of rainfall between the long rain season and short rain season, while in RII dry conditions were evident during the transition periods - JF and JJA. The continuation of precipitation in RI during the JF and JJA seasons might be a result of the influence of the coupled lake-land breeze interaction with mesoscale circulations generated by differential thermal heating of the land surface (Baidya Roy \& Avissar 2002). This might also explain the differences in precipitation in the 3 years during JJA. The contrast in land cover generated by increased agricultural activities (Fig. 2) might have led to differential thermal forcing over the years, hence resulting in different potential evaporation and precipitation rates forced by different surface fluxes (Fig. 7). To further investigate the role of vegetation (land use) changes on precipitation and temperature variability in the region, we performed a suite of sensitivity experiments using the RegCM4 model as discussed in the subsequent sections.

\subsection{Simulated sensitivity of hydroclimatic variables to land surface perturbations}

\subsubsection{Observed and simulated East Africa rainfall}

In this section, we try to identify strengths and weaknesses of the RegCM4 in capturing the primary features of the observed rainfall patterns in the region. Fig. S1a-1 in the Supplement (www.int-res. com/articles/suppl/c052p077_supp.pdf displays observed (CRU and GPCP) and simulated JF, MAM, JJA, and OND seasonal rainfall. During the JF season, precipitation is mainly concentrated in the southern part of our domain, which is consistent with earlier observation studies, e.g. Nicholson (1996). This is well captured in both observations (CRU and GCPC) (Fig. S1a,b) and in the model simulations (see Fig. S1c). From the observations, CRU precipitation data indicate a high precipitation center along the east coast of Tanzania in MAM (Fig. S1d); however, GPCP precipitation data (Fig. S1e) do not capture the high rainfall amount over southeastern Tanzania shown in the CRU. RegCM4 simulations capture maximum precipitation centers over the western part of our domain and over the Congo extending to Uganda. However, precipitation is underestimated over most parts of our domain during MAM. During
JJA, precipitation is mainly concentrated on the western side of the region, around Lake Victoria. Both observations, CRU and GPCP (Fig. S1g,h), show maximum JJA precipitation around the lake region and over most of Uganda. This is also well captured in the RegCM4 simulation (Fig. S1i). OND is the second rainfall season over the region. As in MAM, OND-simulated precipitation is underestimated over the northeastern part of Kenya but well simulated over the western side of the domain (Fig. S1j-1). While modeled precipitation rates are lower than those observed, the model captures the observed precipitation maxima over the western part of our domain and the Congo. Excessive rainfall over Lake Victoria has been shown in earlier regional climate model simulations (Anyah \& Semazzi 2004, 2007) due to lake-induced local convection. However, in our simulation, precipitation over the lake region is less than that observed. This may be due to the fact that our simulations were carried out with the interactive 1D-lake model turned off. Nonetheless, RegCM4 simulation captures the important features of the seasonal rainfall over the region. Moreover, the model is quite consistent with observations over the western parts of the domain, including western Kenya, northwestern Tanzania and Uganda. Despite the highlighted deficiencies, the model is capable of sufficiently capturing the seasonal rainfall cycle, and we are confident of the sensitivity simulation results discussed in the present study.

\subsubsection{Simulated precipitation and temperature changes}

To examine the impact of vegetation changes on the regional climate of Kenya, we carried out RegCM4 simulations with 2 different vegetation scenarios. Simulations are performed with a counter change in agricultural land cover and forests over the western part of Kenya extending between longitude $34^{\circ}-38^{\circ} \mathrm{E}$ and latitude $2^{\circ} \mathrm{S}-1.5^{\circ} \mathrm{N}$. Our main objective in the present study was to investigate the impact of agriculture intensification over the region (particularly western Kenya) on hydroclimatic variables during the seasonal rainfall periods. Hence, our hypothesis was that agricultural intensification over the western part of Kenya leads to a reduction in seasonal precipitation over the region. Our simulation was first done with the unmodified land cover data (Fig. 8a) in the RegCM4 model, hereafter referred to as the control experiment (CE). We then modified the model land cover (Fig. 8b) to reflect the changes in 

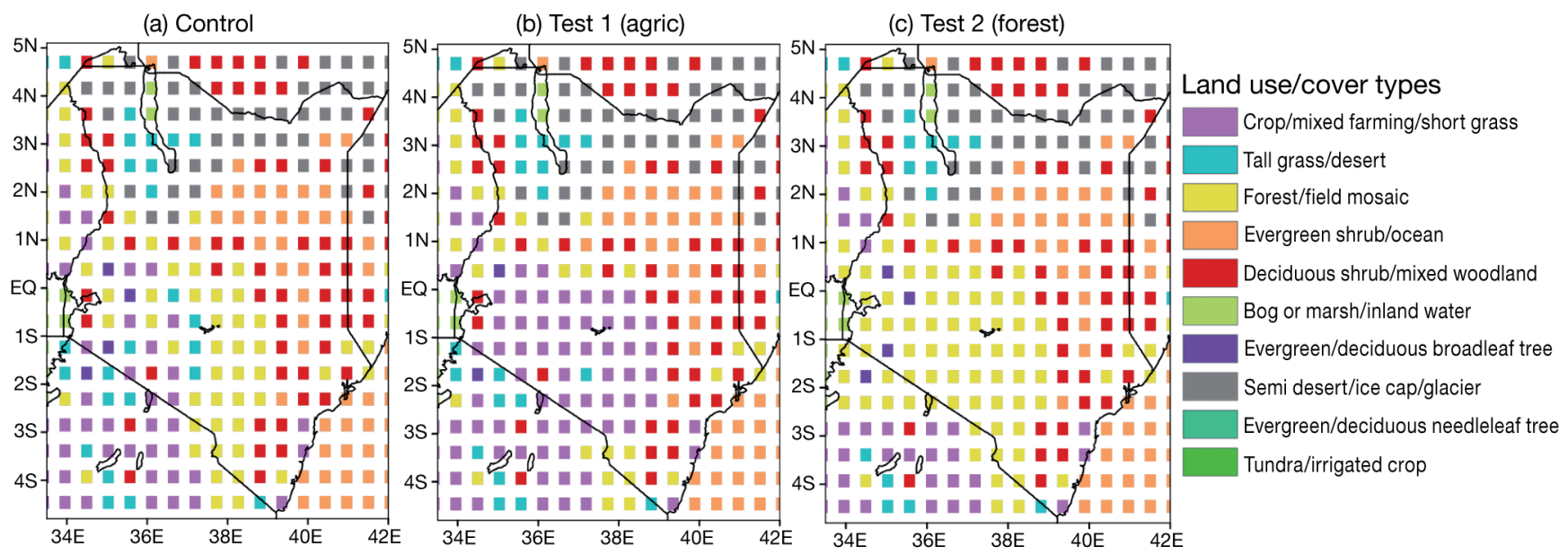

Fig. 8. Model land use and cover plots (a) as in the model, (b) Sensitivity Experiment 1, agricultural expansion, and (c) Sensitivity Experiment 2, reforestation

agricultural land cover as shown in Fig. 2 of our land cover classification. This was the first sensitivity experiment (SE1). The second sensitivity experiment (SE2) involved changing agricultural areas to forest cover (Fig. 8c).

Fig. 9 shows the averaged precipitation differences (1991-2000) between the control and sensitivity experiments (CE-SE) for April and November, the peaks of the MAM and OND rainfall seasons, respectively. From the plots (Fig. 9) changes in precipitation as a result of land cover modifications vary, with large areas around the lake region significantly affected. Statistically significant (at 0.1 level) negative changes in precipitation as a result of increased agricultural activities are simulated around Lake Victoria in April (Fig. 9a). The default land use/cover category applied in the model show the lake region to be characterized by a mixture of deciduous broad-leaf trees, deciduous shrubs, a forest/field mosaic, and crop/mixed farming. The reduction in precipitation over the area might therefore be attributed to reduced surface roughness, which leads to increased wind speed over the area likely transporting moisture to forested zones and inhibiting local moisture convergence. Indeed our plot of moisture flux divergence and wind vector differences shows divergences around the lake region at the $950 \mathrm{mb}$ level indicating increased wind speed toward the forested area (Fig. S2a in the Supplement). On the other hand, significant increase in precipitation was also simulated over the same region with changes of land cover to forest (Fig. 9b). This can also be attributed to wind dynamics and changes in convergence centers (Fig. S2b).

Earlier studies (e.g. Camberlin \& Philippon 2002) showed that the MAM rainy season is mainly influ- enced by local mesoscale circulation factors. Further, MAM seasonal rainfall reaches its peak in April; hence large-scale interactions with local forcing factors can be expected to be more active during the peak of the rainfall season in April. This is also consistent with the apparently stronger sensitivity of April precipitation to changes in local forcing mechanisms such as land cover changes, compared to March and May. This also confirms our initial assertion that spatial rainfall distribution is sensitive to land cover changes. Similarly, during the OND rainfall season, significant changes in simulated precipitation occur as a result of land cover perturbations over the same area, as occurred during the month of April (Fig. 9c,d). While in April, local climatic control factors are dominant (Camberlin \& Philippon 2002), in November, the effects of large-scale climatic control are more dominant over the region (Ogallo 1988, Mutai et al. 1998, Indeje et al. 2000). Nonetheless, there is significant impact of land use changes during the peaks of the 2 predominant rainfall seasons (MAM and OND).

Simulated ground temperature changes in the perturbation experiment were also significant over the same region at the 0.1 confidence level (Fig. 10a-d). An increase in surface temperature of about $0.4^{\circ} \mathrm{C}$ was simulated around the lake region both in April and November, as a result of changes in land cover from forest to crop/mixed farming (Fig. 10a-c). However, during November, a unique change in temperature pattern was simulated when land cover types were converted to agricultural types. Temperature increased around the lake region when land cover/ use was converted from forest to crops (Fig. 10c), while, over the forest region, a significant decrease in 


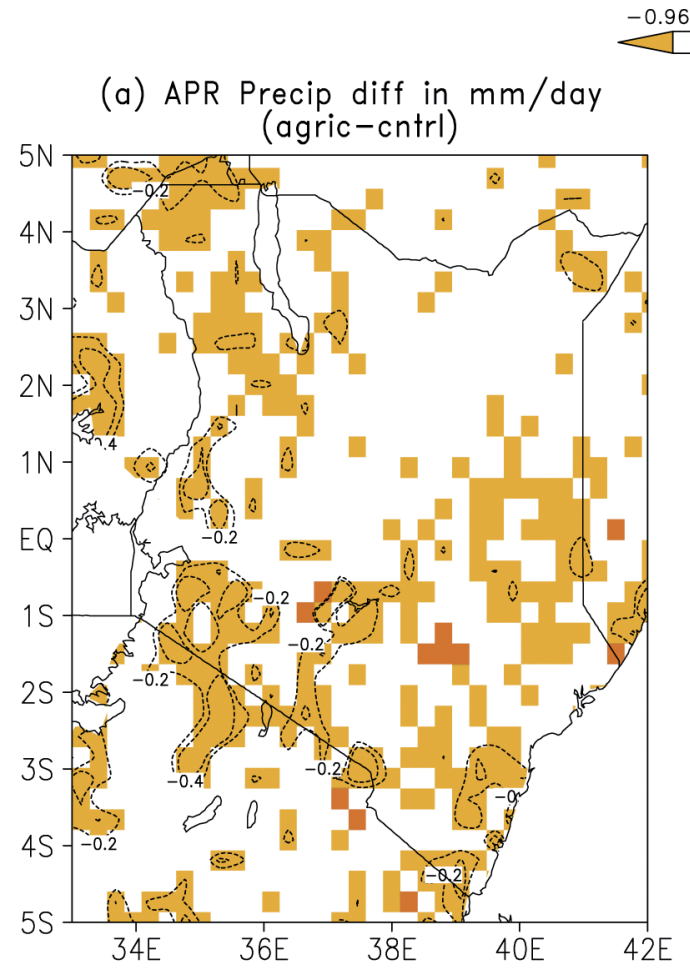

(c) NOV Precip diff in $\mathrm{mm} / \mathrm{day}$

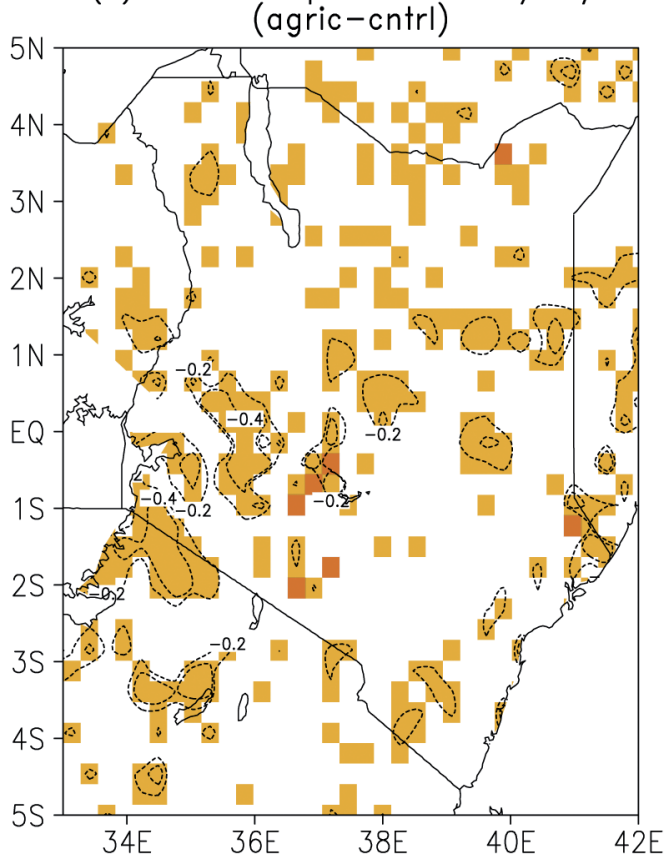

(b) APR Precip diff in $\mathrm{mm} /$ day

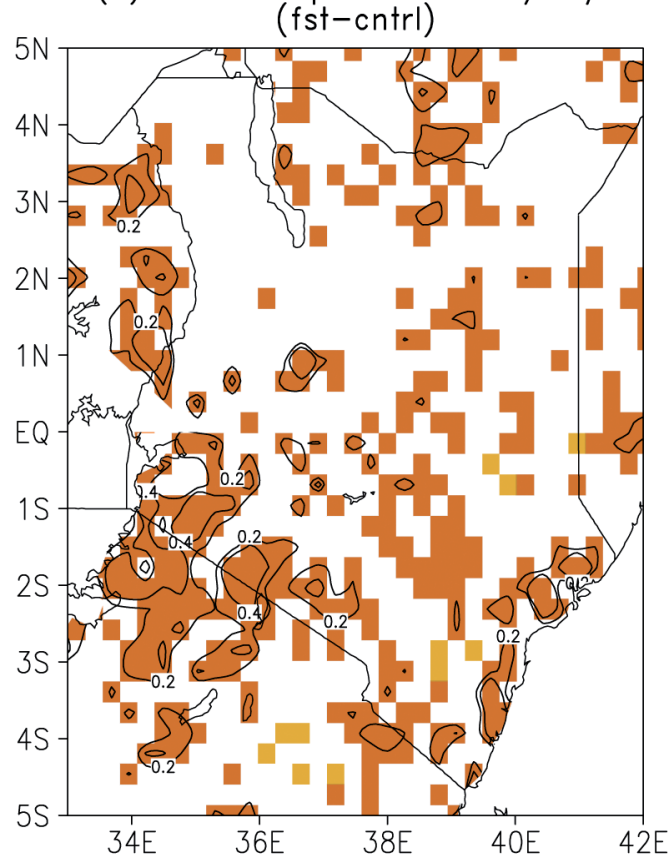

(d) NOV Precip diff in $\mathrm{mm} /$ day

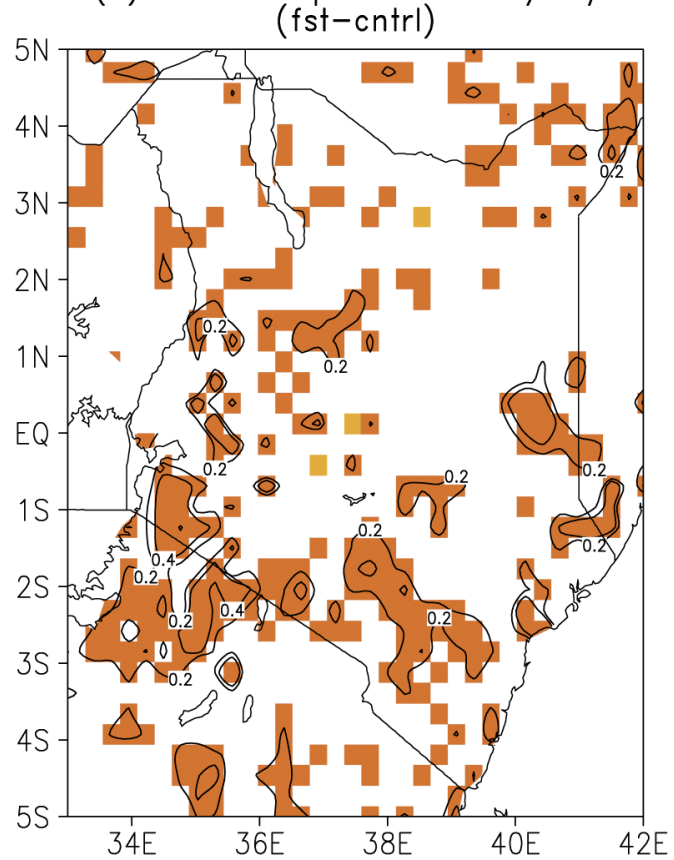

Fig. 9. Averaged (1991-2000) precipitation difference $\left(\mathrm{mm} \mathrm{d}^{-1}\right)$ for (a) April, agriculture minus control (agric - cntrl), (b) April, forest minus control (fst - cntrl), (c) November, agric - cntrl, and (d) November, fst - cntrl. Shading: areas where Student's $t$-test values are statistically significant (at the 0.1 level). Solid contours: positively changed area; dotted contours: negatively changed areas

temperature was simulated in November (Fig. 10c). Nonetheless, under the assumption of reforestation, a significant temperature decrease was simulated around the lake region, extending to southwestern
Kenya. The simulated ground temperature changes can be attributed to changes in surface fluxes, especially LHF, as discussed in detail in the following sections. 


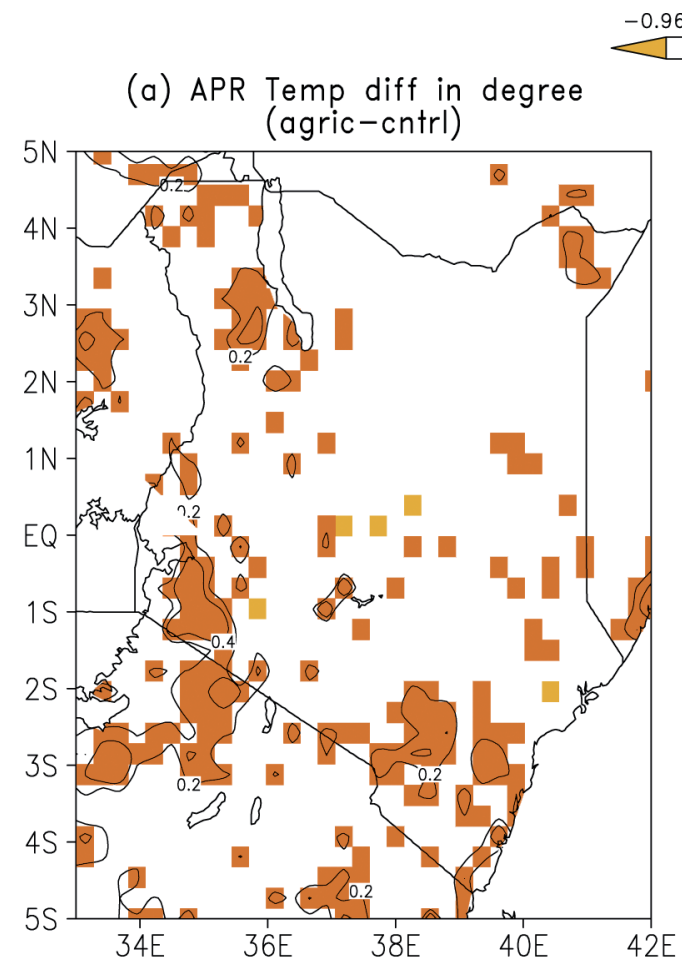

(b) APR Temp diff in degree

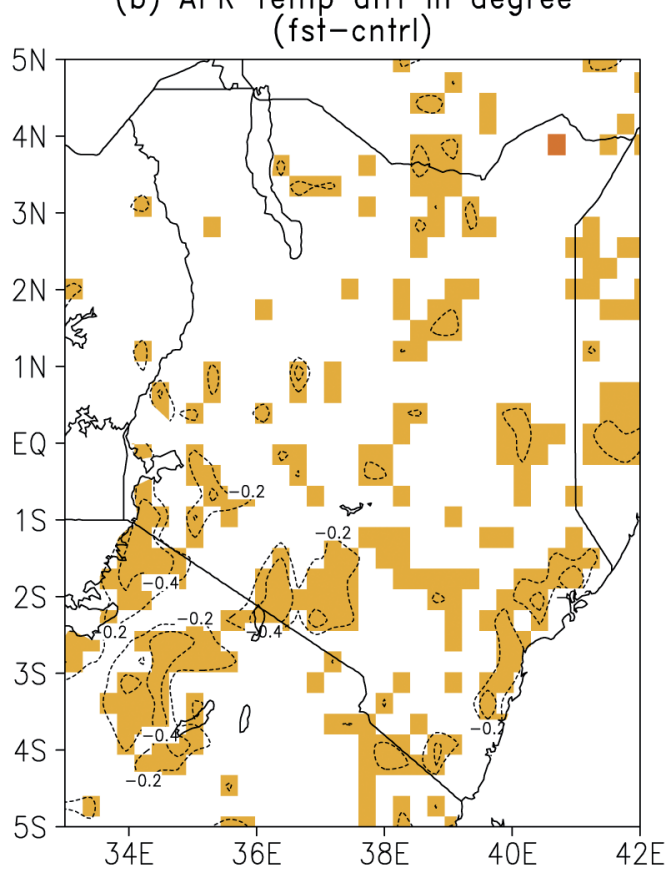

(c) NOV Temp diff in degree

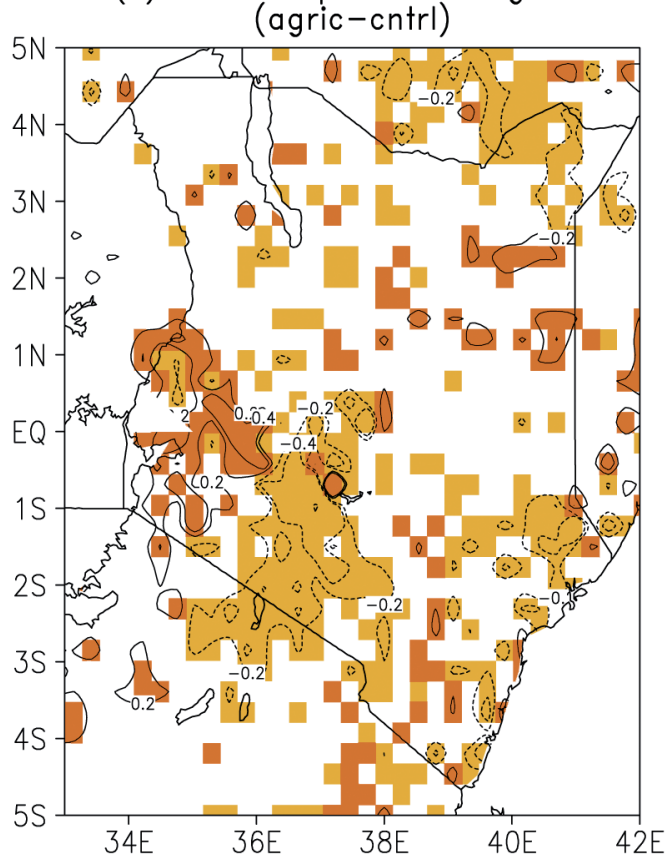

(d) NOV Temp diff in degree

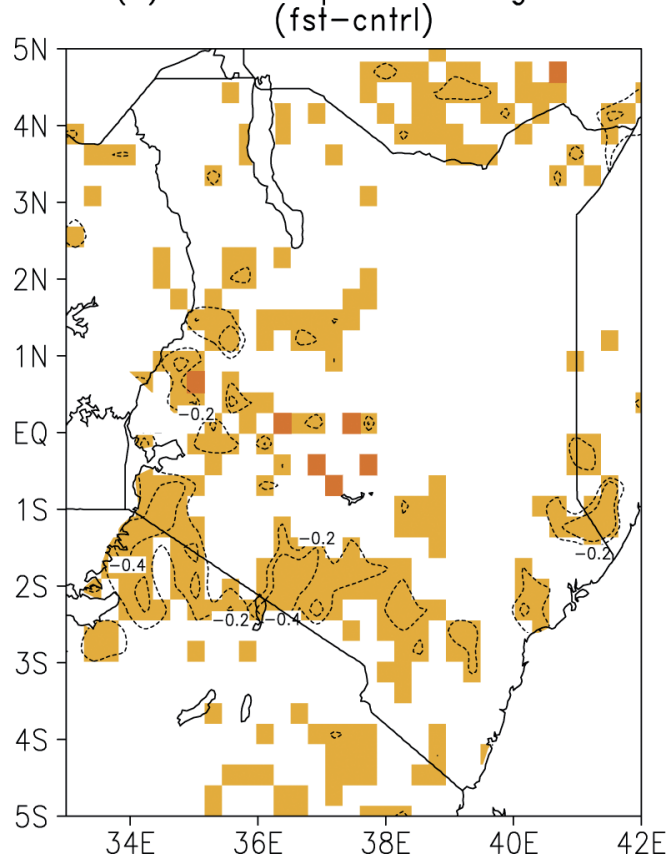

Fig. 10. Same as Fig. 9, but for ground temperature $\left({ }^{\circ} \mathrm{C}\right)$

3.3.3. Response of

surface fluxes to land use changes

Fig. 11 shows the difference in April surface flux between the forest/agriculture and CEs for the SHF $\left(\mathrm{W} \mathrm{m}^{-2}\right)$, LHF $\left(\mathrm{W} \mathrm{m}^{-2}\right)$, long-wave cooling rate $\left(\mathrm{W} \mathrm{m}^{-2}\right)$, and surface-absorbed solar flux $\left(\mathrm{W} \mathrm{m}^{-2}\right)$. Analyses of the surface absorbed solar flux (SAbSF) and surface long-wave cooling (LWC) are done under clear-sky conditions. Note that under these conditions the incoming solar radiation was the same in all experiments. However, significant changes (at the 0.1 level) 

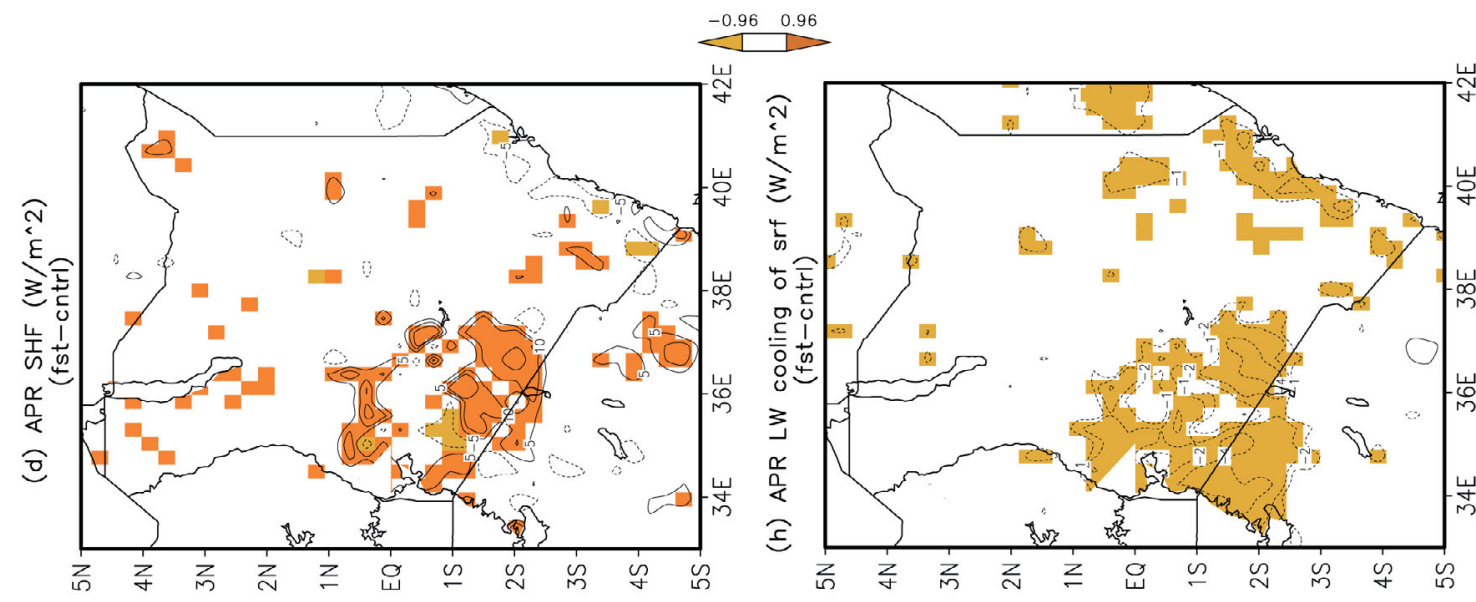

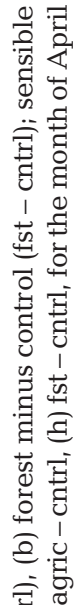
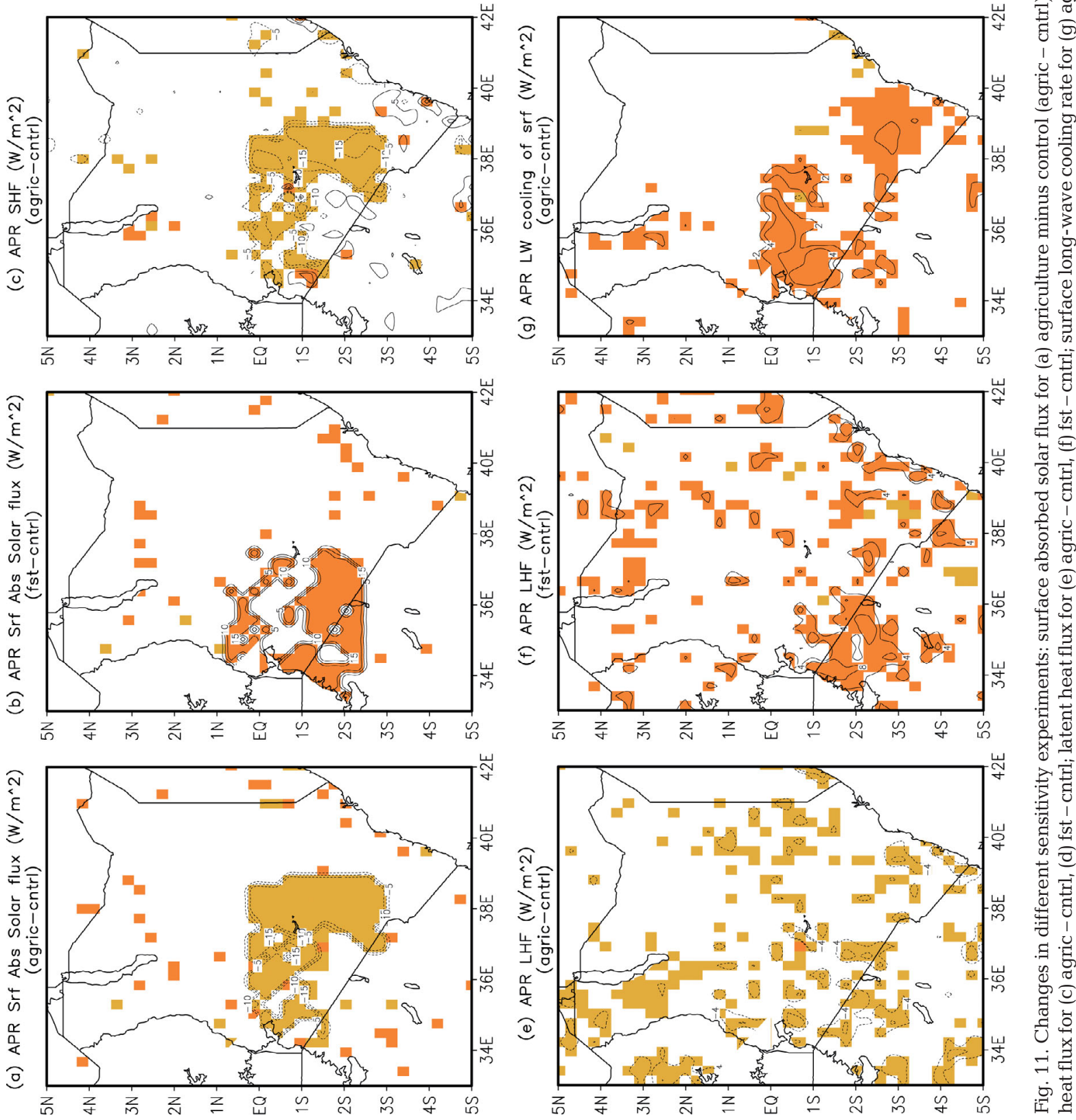
in SAbSF were simulated in both SE1 and SE2 experiments. In SE1 (Fig. 11a), significant decrease in SAbSF was simulated over the forested areas and some areas around the lake region. In SE2 (Fig. 11b) a significant increase in SAbSF was simulated over SW Kenya and around the lake region. The changes in SAbSF were directly reflected in the changes in surface net radiation flux (NRF), with a decrease in NRF simulated in SE1 and an increase in SE2.

A significant property of tropical forest is its very low surface albedo (Zhang et al. 1996). Replacing forest with crops, therefore, leads to an increase in surface albedo which causes a direct reduction in net surface radiation (Mabuchi et al. 2005a,b), due to the decrease in absorbed solar flux (Fig. 11a). An average increase of about $15 \mathrm{~W} \mathrm{~m}^{-2}$ in SAbSF was simulated in the SE2 experiment, and an average decrease of about $3 \mathrm{~W} \mathrm{~m}^{-2}$ was simulated in SE1 experiment. The reduction in net radiation in SE1 would, therefore, be associated with increased surface albedo. Crops generally have high reflectivity as compared to the forest canopy (Monteith \& Unsworth 2008). Thus, surface vegetation plays a role in the portioning of net radiation into LHF and SHF (Chase et al. 2000, Bounoua et al. 2002). Significant changes in SHF and LHF were simulated in both SE1 and SE2 due to changes in NRF. In SE1, a significant decrease in SHF (Fig. 11c) was simulated over forested areas, while in SE2 a significant increase in SHF (Fig. 11d) was simulated over SW Kenya, around the lake region. However, changes in LHF in SE1 (Fig. 11e) were scattered with patches of significant decrease in LHF over SW Kenya and around the lake region. Nonetheless, a significant increase in LHF was simulated over SW Kenya in SE2 (Fig. 11f). This signifies that changes of land cover from forest to agriculture/crops lead to a decrease in both SHF and LHF in April (Fig. 11c,e), while the conversion of land cover from agriculture/crops to forests leads to an increase in both SHF and LHF (Fig. 11d,f). Further, changes in LHF were directly reflected in the evapotranspiration pattern, resulting in lower precipitation rates and upper level soil water content in SE1 and enhanced precipitation rates and upper level soil water content in SE2 (figures not shown). Evapotranspiration rates are affected by a number of factors including surface wind speeds, surface temperature, and LHF, while on the other hand LHF is a culmination of surface albedo, surface roughness, soil moisture, and changes of other vegetation properties (Zhang et al. 1996, Bounoua et al. 2002). Hence, lower evapotranspiration rates in the SE1 test can be attributed to increased surface albedo and reduced surface rough- ness. Redistribution of the surface energy balance due to perturbation in surface vegetation also led to changes in surface temperature as shown in Fig. 10. April and November surface LWC shows significant increase (at the 0.1 level) in SE1 (Figs. $11 \mathrm{~g} \& \mathrm{~S} 3 \mathrm{~g}$ in the Supplement, www.int-res.com/articles/suppl/ c052p077_supp.pdf) around the lake region. In SE2 (Figs. 11h \& S3h), a significant decrease in surface LWC was also simulated around the lake region in comparison to the control run. The decrease in LWC in SE2 is a reflection of the lower surface temperatures over the region and is consistent with the surface temperature plot (Fig. 10b,d), while the increase in LWC is likely due to a greater increase in surface temperatures (Fig. 10a). However, in November, surface temperatures increased around the lake region and decreased over forestland areas with the conversion of land cover to agriculture/cropland. This characteristic change in temperature can be attributed to changes in LHFs and SHFs. While the decrease in NRF resulted in a significant decrease in SHF (Fig. S3c) over the forest region in SE1, no significant change in LHF (Fig. S3e) was simulated over the forest region. This signified that the decrease in NRF favored LHF at the expense of SHF. Hence, while SHF decreased, surface cooling by LHF remained unchanged, leading to a drop in surface temperature over the forest region.

Figs. 12 \& S4 (in the Supplement) show a summary of the statistical relationships between surface fluxes for the month of November. In both experiments, SHFs and LHFs increased with the increase in NRF. However, an increase in SHF was accompanied by a reduction in LHF as expected. This is in agreement with NCEP reanalysis plots (Fig. 7). A substantial tradeoff between SHF and LHF for sensitivity experiments on different land use conversions is apparent in our simulations. A decrease in SHF and LHF was realized with a decrease in NRF in SE1 (Fig. 12), while in SE2 (Fig. S4), both SHF and LHF increased with an increase in NRF. However, the portioning of SHF and LHF differed in both cases, with a larger decrease in SHF simulated in SE1 as compared to the decrease in LHF. In SE2, the increase in SHF was almost twice the increase in LHF. The linear relationship between LHF and surface temperature shows an increase in surface temperature with a decrease in LHF in SE1, though with a weak gradient. Similarly, a slow increase in LWC was simulated with an increase in temperature. Nonetheless, a strong gradient existed between surface temperature and LHF in SE2 (Fig. S4). Therefore, an increase in LHF resulted in a decrease in surface temperature, while surface temperatures increased 
with an increase in SHF. Similarly, a decrease in surface temperature resulted in reduced surface LWC. Clearly lower surface temperatures in SE2 were a result of increased LHF at the expense of SHF, similar to SE1 in November over forest zone.

In our 10 yr RegCM4 simulation (1991-2000), while the variability in the simulated surface fluxes followed the observed climatic regimes - with high amounts of LHF, evapotranspiration, and precipitation simulated over wet years such as 1997 and lower amounts of the same variables simulated during the drier years such as 2000 - the variability in the impact of land use/cover changes was independent of large-scale influences such as ENSO events, as there were no large deviations from the control run for either agriculture or reforestation experiments.

\section{SUMMARY AND CONCLUSIONS}

Land cover classification based on Lansat data shows increased agricultural activities replacing
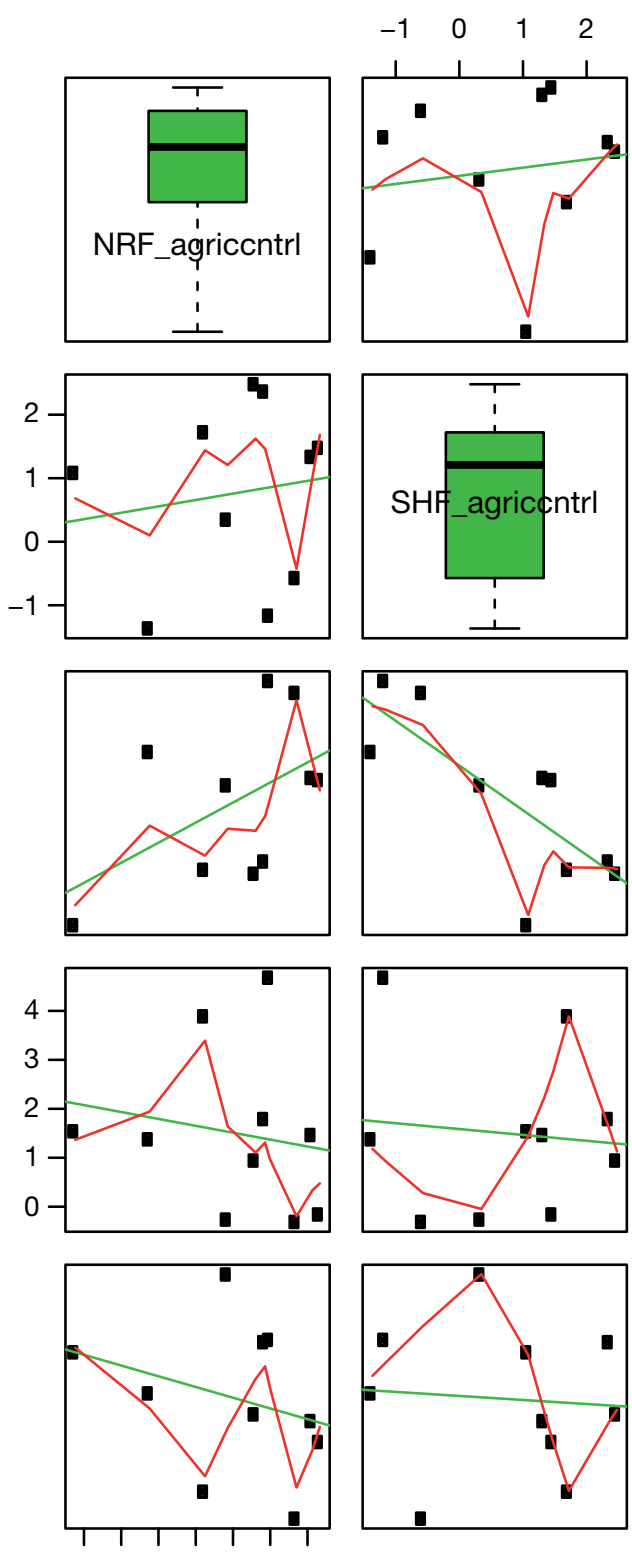

$-2.5$

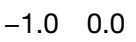

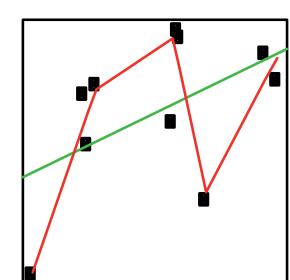
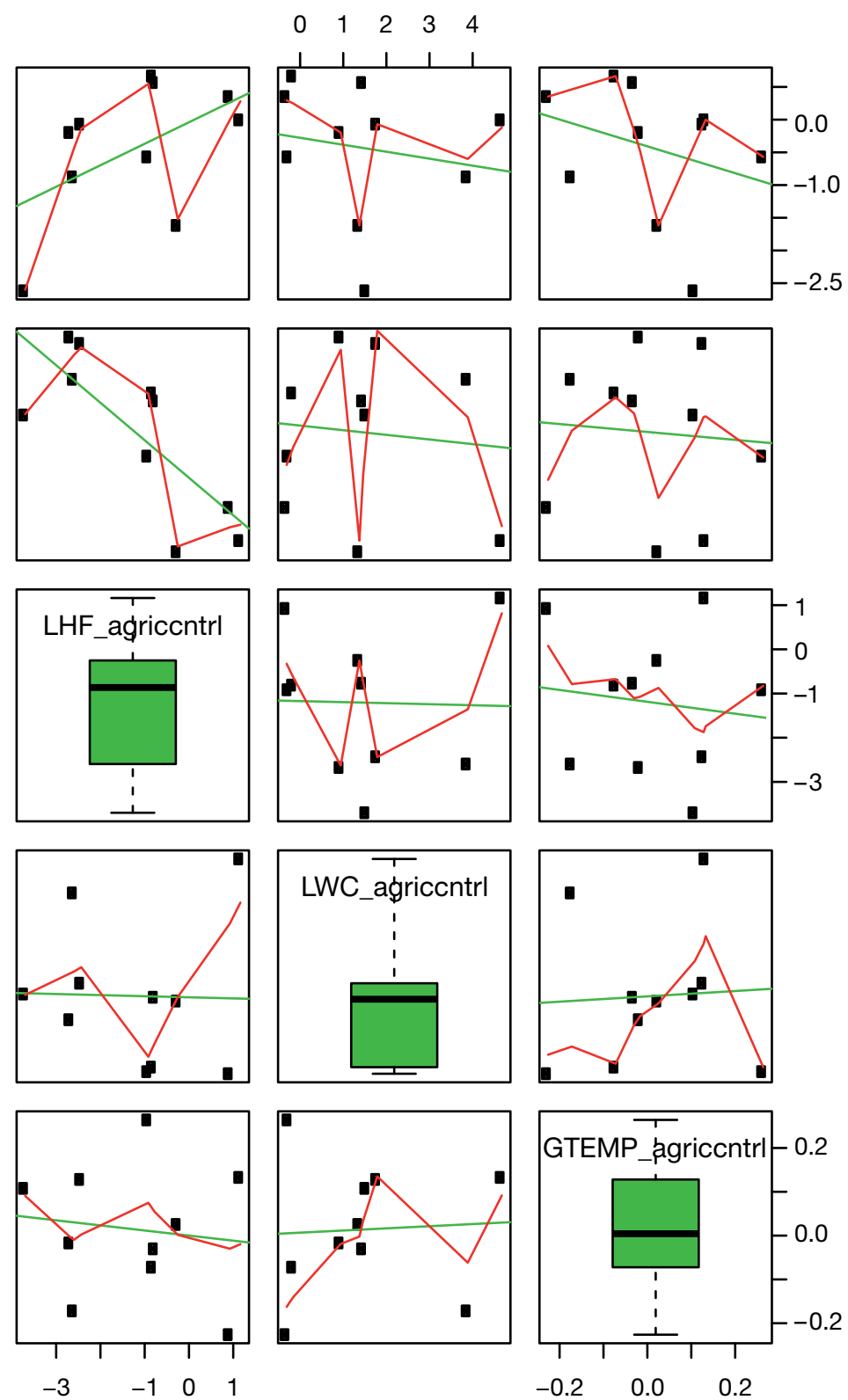

Fig. 12. Relationship of standardized net flux radiation (NRF), sensible heat flux (SHF), latent heat flux (LHF), long-wave cooling (LWC) and ground temperature (GTEMP), anomalies. The relationships are for November differences between the control and agricultural runs 
large portions of forests over the GHA region, particularly in Kenya, between the years 1986 and 2000. For example, by 1986 agricultural activities were mainly concentrated on the western and Rift Valley parts of the county, covering about $6.55 \%$ of the total land mass. By 2000, agricultural activities intensified and expanded to other parts of the country, extending coverage to about $17.89 \%$ of the land mass. At the same time, our analysis also shows a decrease in the land area under forest coverage. We attribute this to an increase in population which has led to encroachment on the forest as the demand for agricultural land increased. However, the encroachment on forestland cannot be blamed wholly on the population increase, but also as an adaptive measure to cope with the effects of climate variability and climate change. This led us to the second aspect of our study that involved examining the relationships among climatic factors, rainfall and temperature, and land use/land cover changes using both observations and RegCM4 mechanistic/sensitivity simulations.

Spatial analysis of the observed precipitation distribution shows higher rainfall over western Kenya, especially over the Lake Victoria region; these areas correspond to the location of agricultural zones. In addition, the main forests/dense vegetation areas are also located in the same regions. The lake region experiences precipitation throughout the year, as shown by our analysis of 1986, 1995, and 2000. This can be attributed to the lake-induced circulation that also enhances localized convection and rainfall.

Intensive agricultural activities have been suggested as a cause of precipitation decline over Kenya. From our RegCM4 runs, a significant reduction in precipitation was simulated near the lake region when forestlands were converted to agriculture, while increased precipitation was simulated over the same region when the opposite was done (i.e. converting more cropland to forestland). With significant changes of forestland around the lake region to agriculture, the surface albedo increased, which apparently caused a reduction in the net surface radiation. The uniform and smoother surface caused by shorter agricultural crops led to a decrease in surface roughness, which is the primary factor that determines the aerodynamic exchange between the land surface and the lower atmosphere. This leads to a decrease in evapotranspiration, which is a vital link in the hydrologic cycle processes through recycled precipitation. On the other hand, conversion of cropland to forest led to a reduction in surface albedo and a net increase in net radiation, which, in the long run, led to an increase in evapotranspiration, a possible increase in precipitation, and a reduction in surface temperature.

Further, changes in precipitation were also detected due to a shift in moisture convergence/ divergence zones. Our simulations showed changes in moisture flux convergence/divergence in both land use sensitivity experiments. This means that vegetation perturbations/land use changes can either play a role in amplifying or suppressing large-scale atmospheric effects such as horizontal moisture flux convergence/divergence. However, in our $10 \mathrm{yr}$ long continuous simulation, the variability in the simulated surface fluxes followed the observed interannual climate patterns, with high amounts of LHF, evapotranspiration, and precipitation simulated during wet years such as 1997/1998 and lower amounts of the same variables simulated during the observed dry years such as 2000 . Nonetheless, we do not completely rule out different responses of climatic variables due to land surface perturbation under different climatic regimes as this has been observed elsewhere as in the case of Zeng et al. (1999). More detailed investigations using fine-resolution regional climate models and many more land use/cover scenarios (beyond the scope of the present study) would, therefore, aid in exploring the multitude of mechanisms associated with the complex influences of a heterogeneous land surface on regional/local climate. Longer runs that encompass several different climatic regimes such as ENSO and Indian Ocean dipole years could also be necessary to disentangle the complex land use-climate relationships observed.

Acknowledgements. This research was supported by the National Science Foundation (NSF) Grant AGS 0854615. We greatly acknowledge the help received from the University of Connecticut's LERIS laboratory group, especially from D. L. Civco, J. Parent and J. D. Hurd. Finally, we acknowledge the invaluable comments made by $\mathrm{S}$. Anji and 3 anonymous reviewers.

\section{LITERATURE CITED}

Adler RF, Huffman GJ, Chang A, Ferraro R and others (2003) The Version-2 global precipitation climatology project (GPCP) monthly precipitation analysis (1979present). J Hydromet 4:1147-1167

Anyah RO, Semazzi FHM (2004) Simulation of the sensitivity of Lake Victoria basin climate to lake surface temperature. Theor Appl Climatol 79:55-69

Anyah RO, Semazzi FHM (2007) Variability of East African rainfall based on multiyear RegCM3 simulations. Int $\mathrm{J}$ Climatol 27:357-371

Arino O, Vermote E, Spaventa V (1998) Operational atmospheric correction of Landsat TM imaginary. ESA Earth Obs Q 56:32-35

Baidya Roy S, Avissar R (2002) Impact of land use/land cover 
change on regional hydrometeorology in Amazonia. J Geophys Res 107(D20):1-12

Baldyga TJ, Miller SN, Driese KL, Maina-Gichaba C (2007) Assessing land cover change in Kenya's Mau Forest region using remotely sensed data. Afr J Ecol 46:46-54

Beltrán-Przekurat A, Pielke Sr RA, Eastman JL, Coughenour MB (2011) Modelling the effects of land-use/land-cover changes on the near-surface atmosphere in southern South America. Int J Climatol. doi: 10.1002/joc.2346

Bounoua L, DeFries R, Collatz GJ, Sellers P, Khan H (2002) Effects of land cover conversion on surface climate. Clim Change 52:29-64

> Camberlin P, Philippon N (2002) The east African MarchMay rainy season: associated atmospheric dynamics and predictability over the $1968-97$ period. J Clim 15: 1002-1019

> Camberlin P, Janicot S, Poccard I (2001) Seasonality and atmospheric dynamics of the teleconnection between African rainfall and tropical sea-surface temperature: Atlantic vs. ENSO. Int J Climatol 21:973-1005

> Chase TN, Roger A, Pielke Sr. Baron JS, Stohlgren TJ (1999) Potential impacts on Colorado Rocky Mountain weather due to land use changes on the adjacent Great Plains. J Geophys Res 104:16673-16690

> Chase TN, Pielke RA, Kittel TGF, Nemani R, Running SW (2000) Simulated impacts of historical land cover changes on global climate in northern winter. Clim Dyn 16: 93-105

Clark B, Pellikka P (2007) Mapping land cover change in the Taita Hills, Kenya, utilizing multi-scale segmentation and object-oriented classification of SPOT imagery. In: Proc Int Geosci Remote Sens Symp 23-28 July 2007, Barcelona, Spain, p 1918-1921 (Piscataway, NJ: IEEE)

DeFries RS, Bounoua L, Collatz GJ (2002) Human modification of the landscape and surface climate in the next fifty years. Glob Change Biol 8:438-458

Dickinson RE, Henderson-Sellers A, Kennedy PJ (1993) Biosphere-atmosphere transfer scheme (BATS) Version 1e as coupled to the NCAR community climate model. Tech Note NCAR/TN-3781STR, NCAR, Boulder, CO

Elguindi N, Bi X, Giorgi F, Nagarajan B and others (2011) Regional climate model RegCM user manual, Version 4.1. Abdus Salam ICTP, Trieste

Feddema JJ, Oleson KW, Bonan GB, Mearns LO, Buja LE, Meehl GA, Washington WM (2005) The importance of land-cover change in simulating future climates. Science 310:1674-1678

> Ge J, Qi J, Lofgren BM, Nathan M, Torbick N, Olson JM (2007) Impacts of land use/cover classification accuracy on regional climate simulations. J Geophys Res 112: D05107. doi:10.1029/2006JD007404

Ge J, Qi J, Lofgren B (2008) Use of vegetation properties from EOS observations for land-climate modeling in East Africa. J Geophys Res 113:D15101. doi:10.1029/ 2007JD009628

Gibbard S, Caldeira K, Bala G, Phillips TJ, Wickett M (2005) Climate effects of global land cover change. J Geophys Res 32:L23705. doi:10.1029/2005GL024550

Giorgi F, Mearns LO, Shields C, Mayer L (1996) A regional model study of the importance of local versus remote controls of the 1988 drought and the 1993 flood over the central United States. J Clim 9:1150-1162

Giorgi F, Coppola E, Solmon F, Mariotti L and others (2012) RegCM4: model description and preliminary tests over multiple CORDEX domains. Clim Res 52:7-29
Githui F, Gitau W, Mutua F, Bauwens W (2008) Climate change impact on SWAT simulated stream flow in western Kenya. Int J Climatol 29:1823-1834

Githui F, Mutua F, Willy B (2009) Estimating the impacts of land-cover change on runoff using the soil and water assessment tool (SWAT): case study of Nzoia catchment, Kenya. Hydrol Sci J 54:899-908

Grell GA (1993) Prognostic evaluation of assumptions used by cumulus parameterizations. Mon Weather Rev 121: 764-787

Grell GA, Dudhia J, Stauffer DR (1994) A description of the fifth generation Penn State/NCAR mesoscale model (MM5). Tech Note NCAR/TN-398+STR, NCAR, Boulder, CO

Hastenrath S, Nicklis A, Greischar L (1993) Atmospherichydrospheric mechanisms of climate anomalies in the western equatorial Indian Ocean. J Geophys Res 98: 20219-20235

Halpern D, Woiceshyn PM (1999) Onset of the Somali Jet in the Arabian Sea during June 1997. J Geophys Res 104: 18041-18046

Halpern D, Woiceshyn PM (2001) Somali Jet in the Arabian Sea, El Niño, and India Rainfall. J Clim 14:434-441

> Holtslag AAM, de Bruijn EIF, Pan HL (1990) A high resolution air mass transformation model for short-range weather forecasting. Mon Weather Rev 118:1561-1575

Indeje M, Semazzi FHM, Ogallo LJ (2000) ENSO signals in East African rainfall and their prediction potentials. Int $\mathrm{J}$ Climatol 20:19-46

IPCC (2001) Special report on land use, land-use change, and forestry. Summary for policy makers IPCC, Geneva. www.ipcc.ch/ipccreports/sres/land_use/index.php?idp=1

Kalnay E, Kanamitsu M, Kistler R, Collins W and others (1996) The NCEP/NCAR 40-year reanalysis project. Bull Am Meteorol Soc 77:437-470

Kiehl JT, Hack J, Bonan G, Boville B, Briegleb B, Williamson D, Rasch P (1996) Description of the NCAR community climate model (CCM3). Tech Rep NCAR/TN-420+STR, NCAR, Boulder, CO

Leica Geosystems (2002) ERDAS IMAGINE, Version 8.6. Leica Geosystems, St. Gallen

Li W, Xue Y (2005) Numerical simulation of the impact of vegetation index on the interannual variation of summer precipitation in the Yellow River basin. Adv Atmos Sci 22:865-876

Mabuchi K, Sato Y, Kida H (2005a) Climatic impact of vegetation change in the Asian tropical region. I. Case of the Northern Hemisphere summer. J Clim 18:410-428

Mabuchi K, Sato Y, Kida H (2005b) Climatic impact of vegetation change in the Asian tropical region. II. Case of the Northern Hemisphere winter and impact on the extratropical circulation. J Clim 18:429-446

Maingi JK, Marsh SE (2001) Assessment of environmental impacts of river basin development on the riverine forests of eastern Kenya using multi-temporal satellite data. Int J Remote Sens 22:2701-2729

Memarsadeghi N, Mount DM, Netanyahu NS, Moigne JL (2003) A fast implementation of the ISOCLUS algorithm. In: Proc IEEE Int Geosci Remote Sens Symp (IGARSS'03), Vol 3. IEEE, Toulouse, p 2057-2059

> Memarsadeghi N, Mount DM, Netanyahu NS, Moigne JL (2007) A fast implementation of the ISODATA clustering algorithm. Int J Comput Geom Appl 17:71-103

Mitchell TD, Carter TR, Jones PD, Hulme M, New M (2004) A comprehensive set of high resolution grids of monthly climate for Europe and the globe: the observed record 
(1901-2000) and 16 scenarios (2001-2100). Work Pap 55, Tyndall Centre, Norwich

Monteith JL, Unsworth MH (2008) Principles of environmental physics, 3rd edn. Elsevier, Amsterdam

Mutai CC, Ward MN, Coman AW (1998) Towards the prediction of East Africa short rains based on sea surface temperature-atmosphere coupling. Int J Climatol 18: 975-997

Mutie SM, Mati B, Gadain H, Home P (2005) Land cover change effects on flow regime of Mara River. In: Van de Walle B, Carlé B (eds) Proc 2nd Int ISCRAM Conf. ISCRAM, Brussels, p 237-246

Nicholson SE (1996) A review of climate dynamics and climate variability in eastern Africa. The limnology, climatology and paleoclimatology of the East African lakes. Gordon \& Breach, New York, NY

Notter B, MacMillan L, Viviroli D, Weingartner R, Liniger HP (2007) Impacts of environmental change on water resources in the Mt. Kenya region. J Hydrol (Amst) 343: $266-278$

Ogallo LJ (1988) Relationships between seasonal rainfall in East Africa and the Southern Oscillation. Int J Climatol 8: 31-43

Pal JS, Small EE, Eltahir EAB (2000) Simulation of regional scale water and energy budgets: representation of subgrid cloud and precipitation processes within RegCM. J Geophys Res 105:29579-29594

Pal JS, Giorgi F, Bi X, Elguindi N and others (2007) RegCM3 and RegCNET: regional climate modeling for the developing world. Bull Am Meteorol Soc 88:1395-1409

Pielke RA Sr, Marland G, Betts RA, Chase TN and others (2002) The influence of land-use change and landscape dynamics on the climate system: relevance to climatechange policy beyond the radiative effect of greenhouse gases. Philos Trans R Soc Lond A 360:1705-1719

Serneels S, Said MY, Lambin EF (2001) Land cover changes

Submitted: February 24, 2011; Accepted: September 8, 2011 around a major east African wildlife reserve: the Mara ecosystem (Kenya). Int J Remote Sens 22:3397-3420

Seth A, Giorgi F (1996) Three-dimensional model study of organized mesoscale circulations induced by vegetation. J Geophys Res 101:7371-7391

Seth A, Giorgi F (1998) The effects of domain choice on summer precipitation simulation and sensitivity in a regional climate model. J Clim 11:2698-2712

Simmons A, Uppala S, Dick D, Kobayashi S (2007) ERAinterim: new ECMWF reanalysis products from 1989 onwards. ECMWF Newsl 110:25-35

Sundqvist H, Berge E, Kristjansson JE (1989) The effects of domain choice on summer precipitation simulation and sensitivity in a regional climate model. J Clim 11: 2698-2712

Taylor CM, Lambin EF, Stephane N, Harding RJ, Essery RJH (2002) The influence of land use change on climate in the Sahel. J Clim 15:3615-3629

Uppala S, Dick D, Kobayashi S, Berrisford P, Simmons A (2008) Towards a climate data assimilation system: status update of ERA-interim. ECMWF Newsl 115:12-18

Xue Y (1997) Biosphere feedback on regional climate in tropical north Africa. Q J R Meterol Soc 123:1483-1515

Xue Y, Vasic R, Janjic Z, Mesinger F, Mitchell KE (2007) Assessment of dynamic downscaling of the continental U.S. regional climate using the Eta/SSiB regional climate model. J Clim 20:4172-4193

Zeng N, Neelin JD, Lau KM, Tucker CJ (1999) Enhancement of interdecadal climate variability in the Sahel by vegetation interaction. Science 286:1537-1540

Zhang H, Henderson-Sellers A, McGuffie K (1996) Impacts of tropical deforestation. I. Process analysis of local climatic change. J Clim 9:1497-1517

Zheng XY, Eltahir EAB (1997) The response to deforestation and desertification in a model of West African monsoons. J Geophys Res 24:155-158

Proofs received from author(s): March 2, 2012 